IZA DP No. 6987

Alike in Many Ways: Intergenerational and Sibling Correlations of Brothers' Earnings

Paul Bingley

Lorenzo Cappellari

November 2012 


\title{
Alike in Many Ways: Intergenerational and Sibling Correlations of Brothers' Earnings
}

\author{
Paul Bingley \\ SFI - The Danish National Centre for Social Research \\ Lorenzo Cappellari \\ Università Cattolica Milano \\ and IZA
}

\section{Discussion Paper No. 6987 \\ November 2012}

\author{
IZA \\ P.O. Box 7240 \\ 53072 Bonn \\ Germany \\ Phone: +49-228-3894-0 \\ Fax: +49-228-3894-180 \\ E-mail: iza@iza.org
}

\begin{abstract}
Any opinions expressed here are those of the author(s) and not those of IZA. Research published in this series may include views on policy, but the institute itself takes no institutional policy positions. The IZA research network is committed to the IZA Guiding Principles of Research Integrity.

The Institute for the Study of Labor (IZA) in Bonn is a local and virtual international research center and a place of communication between science, politics and business. IZA is an independent nonprofit organization supported by Deutsche Post Foundation. The center is associated with the University of Bonn and offers a stimulating research environment through its international network, workshops and conferences, data service, project support, research visits and doctoral program. IZA engages in (i) original and internationally competitive research in all fields of labor economics, (ii) development of policy concepts, and (iii) dissemination of research results and concepts to the interested public.
\end{abstract}

IZA Discussion Papers often represent preliminary work and are circulated to encourage discussion. Citation of such a paper should account for its provisional character. A revised version may be available directly from the author. 


\section{ABSTRACT \\ Alike in Many Ways: Intergenerational and Sibling Correlations of Brothers' Earnings *}

We model the correlations of brothers' life-cycle earnings separating for the first time the effect of paternal earnings from additional residual sibling effects. We identify the two effects by analysing sibling correlations and intergenerational correlations jointly within a unified framework. Our multi-person model of earnings dynamics distinguishes permanent earnings from transitory - serially correlated - shocks, allows for life-cycle effects and nests the models of previous research that have focussed either on intergenerational or sibling correlations. Using data on the Danish population of father/first-son/second-son triplets we find that sibling effects explain between one fourth and one half of inequality in life-cycle earnings, and largely account for individual differences in earnings growth. Intergenerational associations account for a considerable share of overall sibling correlations, between 30 and 60 per cent from youth to maturity. We also find that transitory shocks are correlated across family members, in particular between brothers. Extensions of the model show a distinctive effect of mothers' human capital on top of fathers' earnings and no evidence of differential intergenerational transmission between brothers.

JEL Classification: D31, J62

Keywords: intergenerational transmission, sibling correlations, life-cycle earnings

Corresponding author:

Lorenzo Cappellari

Università Cattolica Milano

Largo Gemelli 1

20123 Milano

Italy

E-mail: Iorenzo.cappellari@unicatt.it

\footnotetext{
* We thank Anders Björklund and seminar participants at the University of Milan and the workshop Equality in Crisis, University La Sapienza in Rome, for their comments. Cappellari gratefully acknowledges the hospitality of SFI in Copenhagen. Financial support was provided by the Danish Strategic Research Council (DSF-09-065167). The usual disclaimers apply.
} 


\section{Introduction}

Explaining the inequality of individual outcomes on the basis of family background is the subject of a vast literature in economics, sociology and other disciplines. Solon (1999), Björklund and Jännti (2009) and Black and Devereux (2011) document the progress made by economists in this field over the past twenty years, illustrating various angles from which one can look at the importance of family background. Among these, intergenerational and sibling studies represent two prominent research approaches: the first explicitly considers the parentchild transmission, while the second provides a broader view on family and community influences.

How much of the correlation in sibling outcomes is due to intergenerational transmission? Answering this question is key for understanding the channels through which outcomes are transmitted within the family and informing policy making (Solon, 1999; Björklund and Jännti 2009; Black and Devereux, 2011). Yet, a direct empirical answer to this question is still missing in the literature. This paper provides such an answer by developing an econometric model of intergenerational and sibling correlations in life-cycle earnings.

We contribute to the literature in several ways. This is the first paper that studies intergenerational and sibling correlations of earnings jointly within a unified framework. We draw data from administrative registers of the Danish population and model earnings dynamics within father/first-son/second-son triplets. Using these triplets provides identification of intergenerational effects separately from residual sibling effects within the overall sibling correlation. Our model nests the ones of previous research that have focussed either on intergenerational or sibling correlations.

The siblings and intergenerational literatures have complemented each other over the past twenty years, although indirectly. With a focus on permanent incomes, Solon (1999) shows analytically how the sibling correlation can be decomposed into a part due to intergenerational income elasticity and a residual sibling effect. Subsequent research has been using this decomposition in calibration, by combining statistics of intergenerational and sibling associations estimated for different families and from separate studies. Instead, in this paper we provide a direct decomposition of sibling correlations. We estimate the importance of parental earnings to be much larger than previously thought on the basis of calibrations, by a factor as large as twelve.

Our second contribution is to bring together insights from the sibling and intergenerational literatures with the literature on individual earnings dynamics. Moffitt and Gottschalk (1995) have pioneered an approach to the analysis of individual earnings dynamics 
that has opened up a stream of empirical research. For the first time we apply this approach to the analysis of earnings dynamics of multiple blood-relatives. ${ }^{1}$ Our model allows for individual heterogeneity in earnings growth and serially correlated transitory shocks. In this way we are able to tackle life-cycle biases and transitory shocks, which are the estimation issues plaguing the study of intra-family earnings correlations. Previous studies have dealt with these issues either taking averages of individual earnings over several points-in-time to integrate out transitory shocks or limiting the analysis to a specific age range to mitigate lifecycle biases. Both approaches entail a loss of information. Furthermore, there is a tension between the two approaches in that the time interval required for integrating out shocks of even moderate persistence is longer than the one in which the life-cycle bias is considered minimized. We take an entirely different route and model both sources of bias, which enables us to avoid informational losses and to show how intergenerational and siblings correlations evolve between the ages of 21 and 45, a much longer portion of the life-cycle compared with previous papers.

We also make other contributions to the literature. Our model allows for intra-family correlation of transitory shocks, something that has not been considered in previous intergenerational or sibling research, and which can potentially yield results on the direction of the bias from transitory errors that are opposite to the usual attenuation. In one extension of the model we assess what is the role of mothers' human capital over and above paternal earnings in shaping inequality of permanent earnings. In another extension, we estimate the extent of differential intergenerational transmission between brothers.

Previous research for Denmark has estimated the sibling correlation of permanent earnings to be around 0.25 between the ages of 30 and 40 (Björklund and Jännti, 2009). While confirming this finding, our results show that such correlation varies considerably over the life-cycle, and is larger than 0.3 before age 30 and after the age of 40 . The u-shaped life-cycle pattern is due to the combination of two distinct factors. First, sibling effects (of intergenerational or environmental natures) are the predominant factor determining heterogeneity in earnings growth over the life-cycle. Second there are cross-overs of permanent earnings within birth cohorts: there is a negative association between starting earnings and earnings growth, so that the intra-generational distribution of permanent earnings first shrinks and then fans out over the life-cycle. Since earnings growth is mainly a

\footnotetext{
${ }^{1}$ The one study of multi-persons earnings dynamics that we are aware of is Ostrowsky (2012), who analyzes spouses' earnings in Canada. He builds on the earlier work of Hyslop (2001) who modeled the covariance structure of spouses' earnings in the US, but without allowing for life-cycle effects.
} 
sibling effect, the compression/decompression occurs through the sibling component, generating the u-shaped pattern of sibling correlation.

We find that intergenerational associations account for a considerable share of the overall sibling correlation. This share varies over the life-cycle and becomes prominent after the age of 30. In general, the share of the sibling correlations that can be ascribed to paternal earnings fluctuates between 30 and 60 percent between the ages of 21 and 45, thus being between six to twelve times larger than what has been suggested by previous research for Denmark on the basis of indirect calibrations ( 5 percent).

We also find that transitory shocks are correlated across family members, in particular between brothers. Extensions of the model show a distinctive effect of mothers' human capital on top of fathers' earnings and no evidence of differential intergenerational transmission between brothers.

\section{Related literatures and our contributions}

It is beyond our scope to provide a detailed account of the vast literature on the analysis of family influences and individual outcomes. Rather, in this section we discuss previous studies that are more closely related to our paper and the literatures to which we provide a contribution. $^{2}$

The theoretical background for the analysis of family effects is usually traced back to the contributions of Becker and Tomes (1986). In their model, parents care about the lifetime earnings of their children and maximize utility by choosing between own consumption and investment in child earnings capacity. Offspring outcomes depend also on other productive endowments which are transmitted through the generations. As a result, lifetime earnings are transmitted intergenerationally, through parental incomes and productive endowments.

The works of Solon (1992) and Zimmerman (1992) represent seminal contributions to the empirical research on intergenerational income mobility. Both studies demonstrate that research preceding them substantially underestimated the intergenerational elasticity (IGE) of incomes. This occurs because those studies use measures of parental incomes that are mixtures of long-term incomes and transitory income shocks, the latter being equivalent to classical measurement error. Both authors show that averaging point-in-time data on parental incomes over a limited number of time periods is sufficient to mitigate measurement error and raise the income IGE for the US to substantially higher levels than previously thought, 0.4

\footnotetext{
${ }^{2}$ Recent detailed accounts of the literature are provided by Bjorklund and Jannti (2009) and Black and Devereux (2011).
} 
versus 0.2. Mazumder (2005) further investigates the issue by considering the impact on the estimated IGE of averaging fathers' incomes on longer time windows than the four- or fiveyears used by Solon (1992) and Zimmerman (1992). When transitory shocks are not purely transitory but are characterized by serial correlation, the measurement error on permanent incomes becomes more severe and harder to integrate out, a point already acknowledged both by Solon (1992) and Zimmerman (1992). Indeed, simulations by Mazumder (2005) show that a moderate (0.5) degree of serial correlation in transitory incomes requires 30 years of data for measurement error to be integrated out almost entirely. Using data on sixteen-year income strings for fathers, Mazumder's best estimate of the IGE is 0.6.

Transitory shocks are not the only source of bias in estimating the IGE. Concurrent research on what has come to be known as 'life-cycle bias' demonstrates that variation of long-term income over the life-cycle can also impart a downward bias on the IGEs. This happens because fathers' and sons' incomes are sampled at different phases of the life-cycle, typically too early for sons and too late for fathers, when current measures under- and overestimate (respectively) long-term ones. These issues where initially discussed by Jenkins (1987) in the context of intergenerational analyses, and their implications for estimating the IGE were empirically illustrated by Grawe (2006). Life-cycle bias is an issue not only for intergenerational analyses, but in all those instances in which the researcher is interested in measures of lifetime earnings or earnings but only has access to earnings over a limited part of the life-cycle. Haider and Solon (2006) show that if there is individual heterogeneity in life-cycle earnings growth, then the relationship between current and lifetime earnings varies over the life-cycle, and the bias incurred by using annual in place of lifetime measures is minimized in the 30-40 age range. ${ }^{3}$ In the context of intergenerational analyses, Nybom and Stuhler (2011) show how life-cycle bias gives rise to non-classical measurement error. They show that current strategies for estimating the IGE are still prone to substantial bias, and conclude calling for an explicit allowance for heterogeneous life-cycle growth across individuals in studies of intergenerational income associations.

The strategies that previous studies have suggested for coping with transitory shocks and life-cycle biases conflict with each other. While transitory shocks are better dealt with using long strings of individual earnings, life-cycle bias is minimized over a string of limited length, the ten years between ages 30 and 40. In this paper we follow a different strategy that allows us to eschew the conflict. We use tools from the earnings dynamics literature to model

\footnotetext{
${ }^{3}$ Böhlmark and Lindquist (2006) obtain results for Sweden that are remarkably close to the ones of Haider and Solon (2006).
} 
(rather than averaging out) the two sources of bias, serially correlated shocks and heterogeneous earnings growth. This approach avoids informational losses and allows a characterization of life-cycle effects in intra-family correlations of permanent earnings.

Compared with intergenerational research, sibling studies offer a broader perspective on family and environmental effects. Siblings are “...more alike than a randomly selected pair of individuals on a variety of socioeconomic measurements..." (Griliches, 1979); sibling correlations of earnings provide a measure of all influences that are shared by siblings. These may originate from intergenerational earnings transmission, but may also stem from other factors passed from parents to children that are independent from parental incomes, such as values. In addition, sibling effects capture those influences that are shared by siblings but do not come from the parents, such as (orthogonal) school or community effects. On the other hand, there may be factors transmitted within the family that are not shared by siblings, say because of differential treatment from parents, which are not captured by sibling correlations.

Sibling studies have a well-established tradition in the US economic and sociological literature, see the review in Solon (1999). Solon et al. (1991) show that similarly to intergenerational studies, sibling studies are plagued by measurement error induced by transitory shocks and unrepresentative samples. They report sibling correlations to be much higher than those estimated in most of the preceding US literature. Altonji and Dunn (1991) use a sample of individuals within families to estimate intergenerational and sibling correlations, although they do not analyse them within a unified model as we do in this paper. They find both types of correlations to be substantial and of about the same size, 0.35. Page and Solon (2003a, 2003b) find that family effects matter more than neighbour effects in explaining sibling correlations.

Björklund and Jännti (2009) and Black and Devereux (2011) classify sibling studies as one of the methods for shedding light on the mechanisms behind intergenerational associations. The larger the difference between sibling and intergenerational correlations, the more important environmental factors that siblings share independently of the parents. A formal characterization of the link between sibling income correlation and the IGE is provided by Solon (1999), who specifies a model of child permanent incomes with an idiosyncratic and a sibling component, both assumed constant, and writes the sibling component as a function of fathers permanent income and a residual sibling effect, capturing remaining shared factors independent of father's income. Assuming stationarity in the distribution of permanent incomes of both fathers and sons, Solon obtains the following decomposition of the sibling correlation: 
Sibling correlation $=\mathrm{IGE}^{2}+$ Residual sibling correlation .

Subsequent research has been applying this decomposition as a calibration on the basis of sibling correlations and IGEs sometimes estimated from different families and different studies, finding in general a small effect for intergenerational factors, see e.g. Björklund and Jännti (2009; 2012). Our contribution is to provide the direct counterpart of this decomposition, which we obtain by developing a unitary model of multi-person earnings dynamics within the family.

A well-established tradition of intergenerational and sibling studies based on population register data can be found in Scandinavian countries. Björklund et al. (2009) estimate a model of siblings earnings in Sweden. They draw data on siblings in the 30-40 age range, in order to minimize life-cycle bias, and model serially correlated transitory shocks. They show that the sibling correlation has been declining during the expansion of the Swedish welfare state in the 1960s. Anti-Nielsen et al. (2011) analyse intergenerational mobility in Norway using long strings of data on both fathers and sons. They show that taking averages of fathers' incomes over longer time windows than preceding studies increases the estimated elasticity. Increasing the starting age for fathers' income strings has the opposite effect. Transitory shocks and lifecycle biases can explain both findings. Björklund and Jännti (2009) provide a cross-country overview of findings on intergenerational and siblings correlation of long-term earnings. For Denmark, they report an IGE of about 0.12 and a brother correlation of about 0.23 . In both instances, Denmark ranks at the bottom of the correlation tables, i.e. it appears the country where the influence of family factors is the least important. The authors make use of the Solon (1999) decomposition to assess the importance of parental incomes in shaping sibling correlations, showing that in Denmark the role of parental income is negligible, explaining 5 percent of the overall sibling correlation. ${ }^{4}$ Björklund and Jännti (2012) use Swedish register data and apply the sibling correlation model to a range of traits and outcomes such as IQ, noncognitive skills, height and years of schooling, as well as long-term earnings. They find that sibling correlations in earnings are the lowest, and that the strongest associations characterize height and IQ. They also estimate intergenerational correlations and apply the decomposition

\footnotetext{
${ }^{4}$ Another indirect approach for assessing the role of family characteristics in shaping siblings correlations is provided by Bjorklund et al (2010) who estimate the correlation before and after regressing siblings earnings on family attributes. They report that for Sweden this methods yields a decomposition of siblings correlations similar the one that can be obtained on the basis of the Solon (1999) decomposition equation.
} 
formula of Solon (1999), finding that parental effects account for a small share of the overall sibling correlation irrespective of the trait or outcome considered.

\section{A model of family members' earnings dynamics}

We study earnings dynamics within the family. We focus on men and distinguish three relevant types of family members, fathers (F), first-born sons (S1) and second-born sons (S2), indexed by $\mathrm{h}^{5}$ For each family member, we consider individual log-earnings in deviation (w) from the mean, where the mean varies by year, birth cohort and type of family member. ${ }^{6}$ Logearnings deviations from the mean consist of a permanent (long-term) component (y) and an orthogonal transitory (mean-reverting) shock (v), orthogonality holding by the definition of permanent and transitory components of earnings. The permanent/transitory distinction is crucial in this context in the light of previous research demonstrating that ignoring transitory shocks may downward bias estimates of intra-family earnings covariances. While many previous papers have been integrating out transitory shocks by taking averages of individual earnings over time, in this paper we explicitly model transitory shocks with serial correlation. Total earnings are written as the sum of the two orthogonal components:

$$
w^{h}{ }_{i j t}=y^{h}{ }_{i j t}+v^{h}{ }_{i j t} ; E\left(y^{h}{ }_{i j t}, v^{h}{ }_{i j t}\right)=0
$$

where the indices $\mathrm{i}, \mathrm{j}$, and $\mathrm{t}$ stand for individual, family and time period.

\subsection{Permanent Earnings}

We model permanent earnings by combining insights from the sibling correlations and earnings dynamics literature. In the remainder of this section, first we describe the distinctive features of the models used in these literatures; then we introduce our model.

\subsubsection{Models of permanent earnings in the sibling correlations and earnings dynamics literatures}

The prototypical model used by previous research on siblings specifies permanent earnings of either brother (S1 or S2) as the sum of two orthogonal time-invariant components:

\footnotetext{
${ }^{5}$ Families with more than two sons represent a tiny proportion in the population, see Section 4.

${ }^{6}$ Considering earnings in deviation from yearly means by birth cohort is a flexible way of removing average age effects that may confound the estimation of individual life-cycle profiles, se Baker and Solon (2003). Here we apply the "de-meaning" procedure distinguishing the different types of family members and adjusting for withincohort age differences through quadratic trends, which we achieve by taking residuals from cohort/memberspecific regressions of log earnings on calendar year dummies and quadratic age trends.
} 


$$
\mathrm{y}^{\mathrm{Sb}}{ }_{\mathrm{ij}}=\mathrm{a}_{\mathrm{ij}}+\mathrm{f}_{\mathrm{j}}, \quad \mathrm{b}=1,2 ; \mathrm{a}_{\mathrm{ij}} \sim(0 ; \operatorname{var}(\mathrm{a})) ; \mathrm{f}_{\mathrm{j}} \sim(0 ; \operatorname{var}(\mathrm{f})) \text {, }
$$

see e.g. Solon (1999) and Björklund et al. (2009). The individual-specific parameter $a_{i j}$ captures idiosyncratic components of permanent earnings, whereas the family-specific one $f_{j}$ absorbs all determinants of permanent earnings that are shared by siblings, thus capturing both intergenerational effects and all other sources of sibling similarities in earnings, that we will call residual sibling effects. Intergenerational earnings effects may depend on genetic transmission or on the extent with which fathers are able to transmit their skills and preferences to their sons after birth. Residual sibling effects, on the other hand, include parental influences not captured by earnings transmission, as well as other community effects shared by siblings that are independent of the parents. Schools, friendship networks or other influences operating at the community level are examples of residual sibling effects. We will refer to the effects captured by $\mathrm{f}_{\mathrm{j}}$ (intergenerational and residual sibling) as overall sibling effects.

The two earnings components are drawn from unspecified distributions with variances $\operatorname{var}(\mathrm{a})$ and $\operatorname{var}(\mathrm{f})$. The sibling correlation of permanent earnings $\left(\mathrm{r}^{\mathrm{S}}\right)$ is the ratio between the variance of the sibling component and the total variance of permanent earnings:

$$
r^{s}=\operatorname{var}(f) /(\operatorname{var}(a)+\operatorname{var}(f))
$$

The sibling correlation provides an omnibus measure of family and community effects, i.e. the share of permanent earnings inequality accounted for by family and community background. Identification of the sibling correlation is granted when data are available on siblings earnings over multiple years, the multi-year requirement enabling separation of permanent and transitory earnings.

Recent studies estimating the model of equation (2) have sampled siblings in the age range $30-40$ to mitigate life-cycle biases, see e.g. Bjorklund et al. (2009). This strategy does not eliminate the source of the bias, i.e. individual heterogeneity of life-cycle earnings growth, but rather limits the scope of the analysis to the phase of the life-cycle when the bias is considered minimised. However, by doing so it conflicts with the need to consider long sequences of individual earnings to control the bias stemming from serially correlated transitory earnings shocks. In this paper we eschew the conflict by modelling heterogeneous growth in permanent earnings using tools from the literature on individual earnings dynamics. 
We specify permanent earnings according to a Random Growth model (RG), see e.g. Lillard and Weiss (1979), Hause (1980), Baker (1997) and Haider, (2001). The RG model assumes that individual earnings evolve over the life-cycle according to an individual-specific earnings profile, which is assumed to be linear in age or experience (we use age). Parameters of the linear profile are drawn from a zero-mean unspecified distribution with unknown second moments to be estimated. The RG model allows for two sources of persistent individual earnings differences, namely time-invariant heterogeneity (individual-specific intercepts) and growth rate heterogeneity (individual-specific slopes). ${ }^{7}$ By accounting for heterogeneous earnings growth across individuals, this parameterisation accommodates the recommendations of the life-cycle bias literature that allowance has to be made for individual heterogeneity when studying earnings correlations across family members (see e.g. Nybom and Stuhler, 2012). Focussing on individuals taken in isolation from other family members, previous studies of earnings dynamics have estimated models similar to the following:

$$
y_{i t}=a_{i}+b_{i} A_{i t} ;\left(a_{i} b_{i}\right) \sim(00 ; \operatorname{var}(a), \operatorname{var}(b), \operatorname{cov}(a b)) \text {. }
$$

where $A_{i t}$ is age. ${ }^{8}$ This simple model can capture important features of individual earnings dynamics. Variances of intercepts and slopes of the profile correspond to different sources of earnings heterogeneity that have theoretical counterparts in human capital models, such as heterogeneous returns to schooling (intercepts) and heterogeneous returns to experience (slopes). A relevant parameter is the covariance between intercepts and slopes of the profile. Many studies have found the covariance to be negative. With $\operatorname{cov}(a b)<0$, individuals startingoff with low pay will see their earnings grow faster than initially higher paid individuals, which may either reflect Mincerian cross-overs due to on-the-job training (Hause, 1980), or the willingness of those on fast tracks to accept low paid jobs at labour market entry. Whatever the causes, a negative covariance between intercepts and slopes implies that individual profiles converge at some point after labour market entry. Conventionally, the cross over point of converging profiles can be computed as the age at which permanent variance is minimised (such variance should be zero if all profiles converged

\footnotetext{
${ }^{7}$ Baker (1997) also experiments with individual-specific quadratic profiles, concluding that they do not add much to the analysis compared with linear profiles.

8 Alternatively, studies of individual earnings dynamics have been specifying the permanent component as a random walk process in which individual earnings evolve through the arrival of infinitely lived shocks. See Meghir and Pistafferri (2011) for a detailed discussion of modelling approaches in the literature. Baker and Solon (2003) and Moffitt and Gottschalk (2012) have extended the RG to include a random walk shock; instead, in this paper we extend the model to account for family effects.
} 
contemporaneously), i.e. Age ${ }^{*}=-\operatorname{cov}(a b) / v a r(b)$. The convergence of permanent earnings implies that within a birth cohort permanent inequality of earnings displays a u-shaped profile, and that intragenerational earnings mobility increases up to Age*, and then decreases. While the RG model has been widely used to study individual earnings dynamics, its application to intergenerational or sibling correlations is still unexplored.

\subsubsection{Our model}

We innovate the model of equation (2) in two key directions. First, we identify the intergenerational effect and the residual sibling effect within the overall sibling component. In this way, for the first time we provide a direct assessment of the role of intergenerational earnings associations within the omnibus sibling correlation. It is worth stressing that in this way we identify the transmission of earnings from fathers to sons, and not other channels of intergenerational transmission working independently from father's earnings: therefore our decomposition provides a lower bound to the intergenerational component of sibling correlation. Second, we introduce life-cycle effects using the RG parameterisation, in this way accounting for life-cycle biases. Our model is an extended RG in which intercepts and slopes depend upon individual-specific, intergenerational and residual sibling effects. Sons' earnings are written as:

$$
y^{\mathrm{Sb}}{ }_{\mathrm{ijt}}=\left[\left(\alpha_{\mathrm{ij}}+\mu_{\mathrm{j}}+\delta_{\mathrm{j}}\right)+\left(\beta_{\mathrm{ij}}+\lambda_{\mathrm{j}}+\phi_{\mathrm{j}}\right) \mathrm{A}_{\mathrm{it}}\right] \pi_{\mathrm{t}}, \mathrm{b}=1,2
$$

The earnings profile is linear in age, and intercepts and slopes of the RG depend upon individual and sibling components. Sibling effects have an intergenerational component $\left(\mu_{\mathrm{j}}\right.$ $\left.\lambda_{\mathrm{j}}\right)$ and a residual sibling component $\left(\delta_{\mathrm{j}} \phi_{\mathrm{j}}\right)$. They represent permanent traits of earnings shared between brothers, coming either from their father's earnings, or from residual factors independent of father's earnings. The idiosyncratic component $\left(\alpha_{\mathrm{ij}} \beta_{\mathrm{ij}}\right)$ captures persistent individual-specific deviations from the sibling effect. Considering that we will be using data drawn from a relatively long time period, we also introduce time effects through periodspecific loading factors $\pi_{\mathrm{t}}$.

Each individual- or family-specific parameter of the RG model is drawn from a zero mean unspecified distribution. RG intercept and slopes are correlated within each dimension 
of heterogeneity (idiosyncratic, intergenerational and residual siblings) and are assumed independent between dimensions: ${ }^{9}$

$$
\left(\alpha_{\mathrm{ij}} \beta_{\mathrm{ij}}\right) \sim\left(0,0 ; \sigma_{\alpha}^{2} \sigma_{\beta}^{2} \sigma_{\alpha \beta}\right) ;\left(\mu_{\mathrm{j}} \lambda_{\mathrm{j}}\right) \sim\left(0,0 ; \sigma_{\mu}^{2} \sigma_{\lambda}^{2} \sigma_{\mu \lambda}\right) ;\left(\delta_{\mathrm{j}} \phi_{\mathrm{j}}\right) \sim\left(0,0 ; \sigma_{\delta}^{2} \sigma_{\phi}^{2} \sigma_{\delta \phi}\right)
$$

Identification of intergenerational effects requires father's earnings to be modelled jointly with sons' earnings. We therefore specify a model for father's earnings similar to that of the sons, with the exception of the residual sibling effects that are shared by siblings only and do not feature in father's earnings; residual siblings effects are therefore empirically identified by the availability of both sibling and intergenerational earnings correlations. The model for father's earnings is:

$$
\mathrm{y}^{\mathrm{F}}{ }_{\mathrm{ijt}}=\left[\left(\alpha_{\mathrm{ij}}+\mu_{\mathrm{j}}\right)+\left(\beta_{\mathrm{ij}}+\lambda_{\mathrm{j}}\right) \mathrm{A}_{\mathrm{it}}\right] \pi_{\mathrm{t}}
$$

Having specified a model with age related growth and idiosyncratic, intergenerational and residual sibling sources of heterogeneity in permanent earnings, we can decompose the overall sibling correlation of permanent earnings over the life-cycle $\left(\rho^{S}\right)$ into its intergenerational $\left(\rho^{\mathrm{I}}\right)$ and residual sibling $\left(\rho^{\mathrm{R}}\right)$ components:

$$
\rho^{S}(A)=\rho^{I}(A)+\rho^{R}(A)
$$

This decomposition is the direct counterpart of indirect ones used in previous studies. Another notable difference with previous studies is the allowance for age effects in the correlation of sibling permanent earnings and its components. Details on the decomposition are provided in the Appendix.

\subsection{Transitory earnings}

Previous literature on individual earnings dynamics has used low order ARMA processes to model transitory shocks. Intergenerational or sibling studies, on the other hand, have been mostly resorting to multi-period averaging to integrate out earnings shocks and reducing measurement error biases, choosing the number of periods on the basis of the supposed degree of serial correlation. One exception is the paper by Björklund et al. (2009) who

\footnotetext{
${ }^{9}$ We will relax the assumption of independence between intergenerational and residual sibling components in the robustness analysis of Section 6.
} 
explicitly model correlated shocks as AR(1) processes concentrating on the $30-40$ age range, assuming infinitely lived shocks uncorrelated across siblings.

In this paper we specify member-specific AR(1) processes with innovations correlated across family members:

$$
\begin{gathered}
\mathrm{v}_{\mathrm{ijt}}^{\mathrm{h}}=\tau_{\mathrm{t}} \mathrm{u}_{\mathrm{ijt}}^{\mathrm{h}}=\tau_{\mathrm{t}}\left(\rho_{\mathrm{h}} \mathrm{u}_{\mathrm{ijt}-1}^{\mathrm{h}}+\varepsilon^{\mathrm{h}}{ }_{\mathrm{ijt}}\right) \\
\varepsilon_{\mathrm{ijt}}^{\mathrm{h}} \sim\left(0, \sigma_{\varepsilon h}^{2}\right), \mathrm{u}_{\mathrm{i} 0 \mathrm{jc}}^{\mathrm{h}} \sim\left(0, \eta_{\mathrm{c}} \sigma^{2}{ }_{0 \mathrm{~h}}\right), \operatorname{cov}\left(\varepsilon^{\mathrm{h}}{ }_{\mathrm{ijt}} \varepsilon_{\mathrm{kjt}}^{1}\right)=\sigma_{\mathrm{hl}}, \mathrm{h}, \mathrm{l}=\mathrm{F}, \mathrm{S} 1, \mathrm{~S} 2, \mathrm{~h} \neq 1
\end{gathered}
$$

where we model the initial condition of the transitory process, allow for cohort effects in initial conditions $-\mathrm{c}=\mathrm{c}(\mathrm{i})$ denotes the birth cohort of person $\mathrm{i}-$ and $\tau_{\mathrm{t}}$ is a period specific loading factor. Each family member draws transitory shocks from a member-specific distribution, and shocks are (contemporaneously) correlated across members. Our model, therefore, includes parameters capturing intergenerational and sibling correlations of transitory earnings shocks, which have both been assumed away in the previous literature. Note that if transitory shocks are positively correlated across persons, then the betweenmember correlation of current earnings provides an upward biased estimate of correlations in permanent earnings.

\subsection{Estimation}

The model fully specifies the inter-temporal distribution of permanent and transitory earnings for each family member and between members. The second moments of this distribution are a non-linear function of a parameter vector $\theta$ that contains RG and $\mathrm{AR}(1)$ coefficients, plus period factor loadings on permanent and transitory earnings. Details on moment restrictions are provided in the Appendix. We estimate $\theta$ by Minimum Distance (see Chamberlain, 1984; Haider, 2001). ${ }^{10}$ In order to identify age effects (in permanent earnings) and birth cohort effects (in transitory earnings) separately from time effects, we derive birth-cohort specific empirical earnings moments and stack them up into a single moment vector that enters estimation.

\section{Data and raw correlations of earnings within the family}

\footnotetext{
${ }^{10}$ We use Equally Weighted Minimum Distance (EWMD) and a robust variance estimator $\operatorname{Var}(\theta)=\left(G^{\prime} G\right)^{-}$ ${ }^{1} G^{\prime} V G\left(G^{\prime} G\right)^{-1}$, where $V$ is the fourth moments matrix and $G$ is the gradient matrix evaluated at the solution of the minimisation problem.
} 
We use data from registers of the Danish population between 1980 and 2006. Thanks to the availability of parents' personal identifier, the Danish register enables connecting members of the same family to one another starting from the birth cohort of 1956. Exploiting this information, we derive a sample of father/first-son/second-son triplets. By analogy with the sibling correlations literature that uses samples including singletons, we also consider families consisting of father/first-son couples only. We study men's earnings and do not consider mother/daughter, mother/son, father/daughter, brother/sister or sister/sister earnings associations. Brothers' ordering is determined irrespective of the presence of sisters: for example, we do not make any distinction for whether there is one sister born in-between the two brothers, before or after. We consider full biological siblings sharing both parents according to the medical birth register. In keeping with the sibling correlation literature, we select brothers not too far apart in the life-cycle, which we achieve by limiting the maximum siblings age difference to ten years; we exclude younger brothers from the sample when the age difference exceeds the limit. We focus the analysis on first-born and second-born sons and do not consider sons born after the second, which, anyway, account for a negligible proportion (2 percent) of the overall sample.

We use pre-tax annual earnings, i.e. income from labour. In order to model life-cycle dynamics we require observation of individual earnings strings over time. We focus on prime age men and conventionally set the start of the life-cycle at age 21 and its final point at age 60. We group individuals into 3-year birth cohorts, imputing the central age to each cohort. Imposing a cohort structure on the data is fundamental for separating life-cycle effects from calendar time, and this is the established practice of earnings dynamics studies, see e.g. Baker and Solon (2003). We select fathers born between 1940 and 1960. The youngest cohort group of fathers (born between 1958 and 1960) starts being observed at age 21 in 1980, and reaches age 47 in 2006; the oldest cohorts of fathers (born between 1940 and 1942) is aged 39 in 1980 and turns 60 in 2001, when it leaves the sample. We select first-sons born between 1958 and 1981. Therefore the oldest cohorts of first-sons coincides with the youngest cohorts of fathers (1958-60), whereas the youngest cohorts of first-sons (born 1979-81) starts contributing to the sample at age 21 in 2001. Finally, we select second-sons born between 1961 and 1981, so that their age/cohort structure resembles that of first-sons, with the exclusion of cohorts 19581960. The sample selection by birth cohorts implies that many cohorts are observed for the full 27-year period covered by the data, namely cohorts $1945-47$ to $1958-60$. The minimum span of observation is 6 years, corresponding to birth cohorts 1979-81, observed between 2001 and 2006. 
The combination of these criteria generates a data-set which is described in the left panel of Table 1 for selected years in terms of first and second moments of the annual earnings distribution and average age. On this sample we apply two additional selections which are typical in the earnings dynamics literature. First, we exclude outliers and trim half percentile of the earnings of each year; since the analysis will exploit empirical earnings moments separately by family members, we perform the trimming within the distribution of each type of member. ${ }^{11}$ Secondly, in order to ease identification of earnings profiles we require the availability of at least five consecutive individual data points, a selection rule that is intermediate between the one used by Baker and Solon (2003), i.e. continuous earnings strings for each individual within a cohort, and the approach of Haider (2001), who allows individuals to move in and out of the sample only requiring having two positive but not necessarily consecutive valid observations on earnings. Other than this, we use all valid observations on earnings and exclude zero-earnings observations. The exclusion of zeroearnings observations is common with most of the earnings dynamics literature assuming that earnings are missing at random, and is also applied in the sibling correlation literature by Björklund et al (2009). The final estimating sample resulting from the last set of selections is described in the right panel of Table 1. Trimming outliers and imposing partially continuous income strings has an impact on sample size. There is also an impact on earnings dispersion, while average earnings are not much affected. In total, our sample consists of about 560,000 persons belonging to 245,000 families of which 67,000 are triplets. Individuals are observed for 16 years on average, giving approximately 9 million observations.

We describe raw patterns of earnings associations within the family in Figure 1. The graph is produced using elements of the empirical inter-temporal covariance structure of earnings, which is estimated for each family member and between members. We discard from the analysis empirical second moments that are based on fewer than 100 cases. Intergenerational covariance series are derived averaging father-son covariances for both sons by sons' ages. There are two lines in each panel of the figure; the line labelled "Same age" is derived computing the average of covariances conditioning on the age of fathers being equal to the age of sons, while the line labelled "Fixed age" conditions on the age of fathers being equal to 40. Sibling covariances are derived by averaging brother-brother earnings covariances over age of the younger brother; in this case the "Fixed age" line corresponds to

\footnotetext{
${ }^{11}$ Bingley et al (2012) show that estimates of earnings components models are robust to alternative trimming rules.
} 
an older brother aged 30. Correlations and elasticities are derived by appropriately standardising covariances.

Raw earnings intergenerational and sibling correlations in Figure 1 are low, in line with results from previous research that places Denmark at the bottom of the international rankings of family earnings associations, see e.g. Björklund and Jännti (2009). The life-cycle structure of these raw associations reveals interesting patterns. There is a relevant difference in earnings associations if one contrasts same-age figures with fixed-age ones. Considering the intergenerational evidence, it appears that while the contemporaneous correlation fluctuates in the range between 0.05 and 0.1 with no clear pattern when the son ages from 21 to 44, the associations with a father aged 40 are very low, actually negative, at young ages, and converge to contemporaneous figures when the son approaches the age of 30 . This evidence is a symptom of life-cycle bias: estimating intergenerational correlations between fathers and sons observed at different stages of the life-cycle provides an underestimate of the correlation resulting at comparable ages. The fact that the data allows us to observe the bias suggests that the information derived from the population register provides an adequate basis for controlling the bias.

Remarkable differences between same-age and fixed-age patterns of earnings within the family emerge also when considering sibling associations in Figure 1. This time not only fixed-age series are low at young ages, but there is also a u-shaped life-cycle pattern of sameage associations, which are particularly pronounced at young ages. The u-shaped pattern is consistent with a RG model of earnings dynamics with Mincerian cross-overs, in which siblings share both fixed and time varying components of earnings. The large contemporaneous associations at early life-cycle stages may also reflect correlation of transitory shocks. It is well known that earnings instability is large for young cohorts (see e.g. Baker and Solon, 2003) and it is plausible that siblings are subject to common shocks, for example because of similar local economic conditions at labour market entry.

\section{Results}

We begin the discussion of our results by focusing on estimates of RG and AR(1) parameters; estimated period factor loadings are reported in Appendix Table A1. ${ }^{12}$ Parameters are

\footnotetext{
12 A model with fully unrestricted time effects produced a few negative estimates on the loadings for the transitory component, possibly reflecting the presence of negative empirical moments for the cross-member earnings covariance. Constraining loading factors on the transitory components for 1981, 1982 and 1983 at the 1980 value (=1) resulted in positive estimates of all remaining factor loadings. Estimates of RG and AR
} 
estimated by imposing the moment restrictions implied by the model on empirical second moments of earnings, after excluding moments based on fewer than 100 individuals. We base the analysis on 4778 within-person moments (of which 2468 refer to fathers, 1344 to first sons and 966 to second sons), 11604 father/first-son moments, 8385 father/second-son moments and 6570 brother/brother moments. There are 31337 empirical moments in total.

\subsection{Permanent earnings}

Results for the extended RG model are reported in Table 2. There appears to be substantial variation along all three dimensions of earnings heterogeneity specified in the model: idiosyncratic, intergenerational, and sibling residual. Such heterogeneity, though, manifests itself differently depending upon which aspect of the earnings life-cycle is taken into account. Panel A reports estimated variances of RG intercepts, showing that idiosyncratic heterogeneity and sibling residual correlations are the main factors that shape earnings dispersion at the start of the life-cycle, accounting for about 40 percent each. Panel B reports estimates of growth rates dispersion and depicts a different situation, in which individual heterogeneity plays a negligible role (7 percent of total dispersion of earnings growth) and intergenerational transmission gains relevance (34 percent), while the remaining share of earnings growth heterogeneity is accounted for by residual sibling effects. It is notable that there is less scope for individual heterogeneity in earnings growth compared with initial earnings levels. Family and environmental influences seem to be the main drivers of individual earnings growth, leaving little room for idiosyncratic deviations.

Panel C reports estimated covariances between intercepts and slopes, i.e. the parameters that pick up (Mincerian) cross-overs of earnings profiles, for each of the three dimensions of heterogeneity considered. All covariances are negative, pointing to an overall crossing-over of profiles, supporting the idea that factors normally associated with cross-overs, e.g. training or the willingness to accept low staring wages in exchange for steeper growth, are shared both intergenerationally and across siblings. However, the speed with which cross-overs occur depends on the specific dimension taken into account, as represented by the third column in Panel $\mathrm{C}$ reporting the implied cross-over ages, spanning the ten years between 28 and 38; the overall cross-over point is located at 35 .

These estimates have implications for the evolution of life-cycle earnings inequality, which are represented in Figure 2 by making use of parameter estimates (including time factor 
loadings) to generate predicted variance components. Overall variance of permanent earnings, resulting from the sum of idiosyncratic, intergenerational and residual siblings effects, first decreases and then increases between the ages of 21 and 45, as a result of cross-overs of earnings profiles, with the minimum of overall permanent variance located at 35 . The minimum of variance corresponds to the bulk of profile crossings, i.e. of mobility within the intragenerational distribution of permanent earnings. The figure also reports the overall sibling component and the intergenerational component; the difference between the two is the residual sibling component, whereas the difference between overall permanent variance and the overall sibling component is the individual idiosyncratic component. At age 21 , the variance of permanent earnings depends mainly on idiosyncratic and residual sibling differences, while intergenerational effects account only for 20 percent of total dispersion. As time elapses, the absolute incidence of idiosyncratic components remains constant, which is a consequence of the negligible idiosyncratic effects singled out in earnings growth rates, see panel $\mathrm{B}$ of Table 2. The figure displays an increasing influence of intergenerational effects within overall sibling variance, reflecting the larger impact of intergenerational effects on earnings growth rates compared with that on initial earnings, see again Panel B of Table 2.

An alternative view on the varying influences of intergenerational effects within sibling correlations over time is provided by Figure 3, which decomposes overall sibling correlation into its intergenerational and residual sibling components using equation (8). Overall sibling correlation is high at the start of the life cycle and depends predominantly on residual sibling components. At almost 0.6, this is more than twice that reported for Denmark by previous studies. As individuals age, overall siblings correlation diminishes, and becomes smaller than 0.3 (i.e. a value in line with previous research) precisely in the 30 to 40 age range which previous studies have used for measuring sibling correlations. The reasons for the rapid drop in sibling correlations is the shrinking of the overall intra-generational earnings distribution (Mincerian cross-overs) which is driven by sibling effects, while idiosyncratic effects (that feature at the denominator only of siblings correlations) are constant through the life-cycle. After the cross-over point at age 35 the intragenerational earnings distribution starts opening up again as an effect of heterogeneous earnings growth, and since sibling components explain the most of heterogeneous growth rates, the overall sibling correlation increases. Note also that the cross-over point of earnings profiles is located at age 35 , and that the 30-40 age range will contain many siblings pairs whose members are located on opposite sides (i.e. before and after) of the cross-over point. Hence, while the earnings distribution of the older brother will be opening up, the younger brother's one will be compressing, which further contributes to 
the reduction of siblings correlations in this age range. This effect will cease after the younger brother has passed the cross-over point, and the sibling correlation will start increasing.

A second important fact reported in Figure 3 is the decomposition of the sibling correlation into its intergenerational and residual component. Intergenerational correlations account for about one third of total sibling correlation at the age of 21 , but their share grows rapidly with age because intergenerational effects in earnings growth heterogeneity are quantitatively relevant. By the early 30s, intergenerational effects dominate residual factors shared by siblings, and their share reaches 60 per cent by age 45 . The figure suggests that intergenerational effects account for a larger share of the overall sibling correlations than previously thought on the basis of the Solon (1999) decomposition.

\subsection{Transitory earnings}

Results on the member-specific AR(1) model for the transitory part of the earnings process are reported in Table 3. Transitory shocks for fathers and sons present remarkably different characteristics, namely there is more shock volatility for sons compared with fathers, the corresponding parameter $\sigma_{\varepsilon}^{2}$ almost doubling when fathers and sons are compared. On the other hand shock volatility is not statistically distinguishable between brothers. Bothers' shocks are also positively correlated, the implied contemporaneous correlation coefficient is 0.05 , i.e. one fifth of the siblings correlation of permanent earnings estimated in previous studies for Denmark. This result questions the ubiquitous assumption in siblings studies that transitory shocks are uncorrelated across siblings. Shock correlations between fathers and sons, instead, do not appear sizeable, while they are statistically significant only in the case of younger sons. It is worth noting that positively correlated transitory shocks imply that the correlation of current earnings over-estimates the correlation in permanent earnings. The relatively high brother correlation of raw earnings at young ages depicted in Figure 1 may reflect such over-estimation. There are statistically significant differences in the autoregressive coefficient among all family members, fathers displaying the larger persistence. Overall, differences in the parameters of member-specific distributions of transitory shocks are consistent with age effects like the ones described in Baker and Solon (2003). The last set of parameter estimates refers to initial conditions of the AR(1) process, which are person/cohort-specific. Differences across person (larger initial conditions for fathers) reflect that fact that on average their earnings trajectories are left censored (i.e. initial earnings at age 21 are not observed for fathers born in the cohort group 1955-1957 and earlier) so that the estimated coefficient picks up the accumulation of the process prior to the 
initial observation. Cohort differences resemble the usual finding from earnings dynamics studies that younger cohorts have larger transitory components.

\section{Robustness}

The previous section shows that there is an important role for intergenerational earnings correlation within the overall sibling effect, larger than previously thought on the basis of indirect decompositions. We now subject this result to sensitivity analysis in two ways, by excluding two-member families from the estimating sample and by allowing for correlation between intergenerational and residual siblings effects in the extended RG model.

By analogy with the tradition of sibling studies that used singleton data to increase the precision of estimates -in particular idiosyncratic components-our estimating sample includes two-member families, which contribute to the estimation of both idiosyncratic and intergenerational parameters. Indeed, Section 3 showed that two-member families represent the vast majority in our estimating sample. It is natural to ask oneself whether the relatively large share of intergenerational correlation within total siblings effects is a consequence of the over-representation of two-member families, which can only contribute to estimation of idiosyncratic and intergenerational effects, not of sibling residual ones. Many two-member families will also be single-child, and one may reasonably expect intergenerational transmission to be stronger than in multiple-children families, both because of different sharing of parental resources and of parental preferences. We investigate the sensitivity of results by restricting the sample to father/first-son/second-son triplets and dropping father/first-son (no second son) pairs.

Results are presented in Table 4.1, showing parameter estimates for the extended RG model. The evidence is remarkably similar to that obtained on the full sample. There is some re-adjustment in the shares of idiosyncratic, intergenerational and residual siblings effects within starting earnings and earnings growth heterogeneity, but variations are always lower than 5 per cent, and they do not always go in the direction one might expect on the basis of the discussion of possible bias in the preceding paragraph. For example, the share of residual siblings factors in growth rate heterogeneity decreases when moving from the full to the triplet-only sample, whereas one would expect the opposite if two-member families were inflating intergenerational associations in the full sample. Result stability is confirmed in Figure 4, left panel, which decomposes sibling correlations using the triplets-only estimates. There is some variation with respect to the results from the main sample, e.g. a slightly slower decline of sibling residual effects over the first fifteen years of the observed life-cycle, but not 
so as to change our conclusions on the relative importance of the two components of sibling correlations.

The model of the previous section has been estimated under the assumption of independence between intergenerational and residual sibling effects. Such an assumption may be too restrictive if the residual sibling component absorbs elements of intergenerational transmission that are not fully captured by father's earnings. In addition, environmental factors maybe correlated with father's earnings (or even be caused by them), again leading to violation of the assumption that intergenerational and residual sibling effects are independent. One may worry that correlation between components of the total family effect could distort the decomposition of siblings correlation. Our second robustness check relaxes the assumption of independence and allows for correlation between intergenerational and sibling residual components within each parameter of the RG model (intercepts and slopes).

Results from the RG model with correlated family effects are in Table 4.2, while the implied decomposition of the sibling correlation is reported in the right panel of Figure 4. Parameter estimates show that the covariance of family effects is statistically significant. This covariance is negative for initial earnings and positive for growth rates. We know from the main model that while the influence of intergenerational factors varies depending upon RG parameters (intercepts or slopes), residual sibling effects always play a prominent role. The changing sign of covariances probably reflects the varying relative weight of the two family effects in the RG parameters. Overall, the shares of heterogeneity in initial earnings and earnings growth that can be ascribed to each family effect are rather stable compared with the benchmark estimates of Section 5; the main difference is the increased importance of idiosyncratic effects within growth rate heterogeneity, from 7 to 22 percent. The sibling correlation decomposition of Figure 4 confirms the robustness of benchmark results to correlated family effects.

\section{Nested models}

One useful feature of our model is that it nests the models used by previous studies, namely intergenerational-only models and siblings-only models. ${ }^{13}$ To what extent do these nested models, that exploit only one dimension of family earnings associations, miss a part of the picture? In particular, to what extent do sibling-only models, that have been used by previous

\footnotetext{
${ }^{13}$ Another model that is nested within ours is a model without life-cycle dynamics, which is the model used both in siblings correlation studies and in the Solon (1999) decomposition of siblings correlations. Estimating that model on our data yielded a sibling correlation of 0.35 , of which about 0.1 is due to intergenerational earnings correlation and 0.25 to the sibling residual component.
} 
research as a way to capture all associations going on within the family, both intergenerational ones and those coming from other sources, replicate the overall siblings influence that we found in the previous sections? We now address these questions by imposing restrictions on our more general model.

We present results from nested models in Table 5. We start in Table 5.1 with a model of the intergenerational transmission of earnings. This is obtained from the full model by dropping all parameters referring to sibling residual effects. The model is estimated after excluding brother/brother moments. The model fits patterns of heterogeneity in initial earnings well, in the sense that the share accounted for by intergenerational components is very similar to that estimated with the general model, 22 compared to 18 per cent. One difference is that this model tends to over predict the relevance of intergenerational correlations within life-cycle earnings growth, wrongly attributing to intergenerational effects what is actually a pure sibling effect.

Results on the siblings-only model are in Table 5.2. This time we should expect the share of sibling correlations to inflate by approximately the size of the share of the intergenerational correlation in the main model, as sibling correlations are an omnibus measure that includes intergenerational effects. As can be seen from the results, this is not what happens. Instead, the siblings share either remains constant (intercepts heterogeneity) or declines (growth heterogeneity) compared with the full model, revealing a certain inability of sibling correlations to capture intergenerational commonalities between siblings.

We can also use variants of these nested models to mimic the Solon (1999) decomposition of sibling correlations between the intergenerational elasticity and the residual sibling effect. Recall that the Solon decomposition is based on models of permanent earnings that exclude life-cycle effects and assume stationarity of the permanent earnings distribution across generations. We can reproduce these characteristics in the nested models by specifying permanent earnings as constants, and excluding time effects. Results from this exercise yield a siblings correlation of 0.38 and an intergenerational correlation (which coincides with the IGE due to the stationarity assumption) of 0.09. Substituting these statistics into the Solon's equation yields a share of siblings correlation accounted for by the IGE of 2.1 percent, well below the shares obtained from our model using the same data.

\section{Extensions}

In this Section we further investigate the structure of sibling correlations by focusing on two additional aspects that have been debated in the literature but for which there is still almost no 
empirical evidence. The first aspect is the extent to which residual siblings correlations depend on family characteristics, rather than on effects external to the family. The second aspect is the degree of differences in intergenerational earnings transmission across brothers.

\subsection{Model with mother's schooling}

Previous research (e.g. Page and Solon, 2003a and 2003b) suggests that the family rather than the neighbourhood is the driving force behind sibling correlations. Our results show that there is a substantive share of sibling correlations (the residual sibling effect) that is not associated with fathers' earnings. The question then becomes what are the factors that generate the residual sibling component, and in particular what is the relative importance of additional family influences beyond fathers' earnings. Family characteristics can be seen as additional common components of brothers' earnings. One component that is shared by brothers and is not perfectly correlated with fathers' earnings is mother characteristics. Indeed, our focus on fathers' earnings in the main model is justified by the fact that we want to analyze one specific channel of intra-family associations that is well defined in previous studies, i.e. the intergenerational earnings correlation/elasticity. It is obvious that there may be other channels of intergenerational transmission that are not via fathers' earnings and that, in our model, will be picked up by the residual siblings correlation, implying that our intergenerational earnings correlation is a lower bound on the role that overall intergenerational influences play in shaping total siblings correlation. To gain insights on these issues, we include mother's human capital in the model, proxied by maternal years of schooling. The model for sons' earnings becomes:

$$
\mathrm{y}^{\mathrm{Sb}}{ }_{\mathrm{ijt}}=\left[\left(\alpha_{\mathrm{ij}}+\mu_{\mathrm{j}}+\delta_{\mathrm{j}}\right)+\left(\beta_{\mathrm{ij}}+\lambda_{\mathrm{j}}+\phi_{\mathrm{j}}\right) \mathrm{A}_{\mathrm{it}}+\omega \mathrm{M}_{\mathrm{j}}\right] \pi_{\mathrm{t}}
$$

where $\mathrm{M}_{\mathrm{j}}$ are mother's years of schooling in family $\mathrm{j}$, while $\omega$ is a loading factor for mother's schooling. Identification of $\omega$ requires independence between mother's schooling and the parameters of permanent earnings, which is clearly hard to maintain. The spirit of the exercise, however, is simply to see how the relative importance of residual sibling correlation varies when mother's schooling is included in the model, and not to estimate causal effects. Note also that mother's schooling is time-invariant, therefore its inclusion should exert greater impact in the constant part of the extended RG model. 
Results of this exercise are reported in Table 6. The loading factor on mother's years of schooling is positive and statistically significant. The relative importance of idiosyncratic, intergenerational and residual siblings correlations within initial earnings heterogeneity changes quite substantially (compared with the main model of Table 2) as a consequence of including mother's schooling, see Panel B. In particular, while the share accounted for by fathers earnings is now 24 percent (it was 18 percent), the relevance of residual sibling correlation is greatly reduced (amounting at 18 versus 42 percent in the main model, while the corresponding coefficient approximately halves). This finding illustrates that there is a distinctive contribution of additional intergenerational factors to sibling correlations on top of fathers' earnings, and one can speculate that a full control for all parental influences might leave only a small share of sibling correlations to be explained by non-parental influences. The table also reports results for earnings growth heterogeneity (Panel C), whose composition is relatively unaffected compared with the main model, as expected. ${ }^{14}$

\subsection{Model with differential intergenerational transmission between siblings}

Another issue emerging from discussions of sibling correlations reported by previous studies is the differential treatment of siblings by parents, which may weaken the ability of sibling correlations to capture family effects (see e.g. Björklund and Jännti, 2009). The usual reference in this context are birth order studies showing that first born children exhibit better outcomes compared with younger siblings (Black, et.al., 2005). Björklund and Jännti (2012) show that controlling for birth order effects has little impact on estimated sibling correlations. Whether intergenerational transmission varies with birth order is a different and related question which has received only little attention (Hotz and Pantano, 2011), and we address this now for earnings.

Our analytical set-up allows the analysis of differential intergenerational transmission thanks to the fact that we observe intergenerational earnings moments for each of the two brothers; therefore we can specify intergenerational parameters to be different for the two brothers. We do this by assuming that the age-invariant intergenerational component is sibling-specific, that sibling-specific components are correlated, and that their covariance with the intergenerational slope coefficient is common between siblings ${ }^{15}$ :

\footnotetext{
${ }^{14}$ We also experimented adding number of siblings in the model for sibling earnings, reaching conclusions that are similar to the ones obtained with mother's schooling.

15 The last assumption is in principle unnecessary; however, a model with unrestricted covariance between sibling-specific intergenerational intercepts and the intergenerational slope produced negative estimates for the variance of the former, suggesting lack of identification in the data. Similarly, a model with sibling-specific
} 


$$
\begin{gathered}
\mathrm{y}^{\mathrm{F}}{ }_{\mathrm{ijt}}=\left[\left(\alpha_{\mathrm{ij}}+\mu_{\mathrm{j} 1}+\mu_{\mathrm{j} 2}\right)+\left(\beta_{\mathrm{ij}}+\lambda_{\mathrm{j}}\right) \mathrm{A}_{\mathrm{it}}\right] \pi_{\mathrm{t}} \\
\mathrm{y}^{\mathrm{Sb}}{ }_{\mathrm{ijt}}=\left[\left(\alpha_{\mathrm{ij}}+\mu_{\mathrm{jb}}+\delta_{\mathrm{j}}\right)+\left(\beta_{\mathrm{ij}}+\lambda_{\mathrm{j}}+\phi_{\mathrm{j}}\right) \mathrm{A}_{\mathrm{it}}\right] \pi_{\mathrm{t}} ; \mathrm{b}=1,2 \\
\left(\mu_{\mathrm{j} 1} \mu_{\mathrm{j} 2} \lambda_{\mathrm{j}}\right) \sim\left(0,0 ; \sigma_{\mu 1}^{2} \sigma_{\mu 2}^{2} \sigma_{\lambda}^{2} \sigma_{\mu 12} \sigma_{\mu \lambda}\right) ;
\end{gathered}
$$

Now there are two intergenerational terms in the intercept of the father equation, $\mu_{\mathrm{j} 1}$ and $\mu_{\mathrm{j} 2}$, representing what fathers transmit to the first and second son. Intercepts in each of the sons' equations will include only one of the two sibling-specific components, thus capturing differential intergenerational transmission between siblings. This parameterisation allows testing the hypothesis that intergenerational transmission does not vary across siblings, corresponding to the null hypothesis that $\sigma_{\mu 1}^{2}=\sigma_{\mu 2}^{2}$. The model is estimated on the sample that includes complete (three-member) families only, as otherwise between-sibling differentials may well pick up single-son effects. For this exercise we also exclude twins because birth order effects are of different nature for them.

Results from the model with differential intergenerational earnings transmission across brothers are reported in Table 7. Estimated sibling-specific coefficients show evidence of a marginally greater variance of intergenerational effects for second sons compared to firstsons. However, the two coefficients fall within each other's confidence bands even at $10 \%$ levels of significance, strongly pointing to non-rejection of the null hypothesis of equal transmission. This is reflected in the fact that the shares of idiosyncratic, intergenerational and residual sibling components of earnings intercepts are the same for the two brothers. This finding is also in line with that of Björklund and Jännti (2012) that allowing for birth order effects has little impact on sibling correlations. The model also estimates the cross-brother covariance of sibling-specific intergenerational effects, which is positive, although not statistically significant. Estimates of remaining coefficients of the permanent earnings model are rather stable relative to the main results of Section 5 .

\section{Conclusion}

We have shown that paternal earnings account for a substantive share of the overall correlation of permanent earnings between brothers. This is a much greater share than has

intergenerational slopes produced a negative estimate for the variance of idiosyncratic slopes, and positive and statistically indistinguishable estimates of the variance of sibling-specific intergenerational slopes, so that we resorted to the specification in the text with only age-invariant sibling specific intergenerational effects. 
been found in previous research that has used indirect decomposition methods. One implication is that policy interventions on social environments outside the family may have a limited impact on the inequality of long-term earnings. This is in line with the findings of Page and Solon (2003a and 2003b) that much of sibling correlation in the US is accounted for by the family rather than the neighbourhood.

Another highlight from our research is that there are non-negligible life-cycle effects in sibling correlations. We obtain estimates of the sibling correlations that follow a u-shaped profile between the ages of 21 and 45. Our estimates replicate the findings of previous research for Denmark in the 30 - 40 age range studied by those papers, but show that siblings correlations are much higher both before and after that interval, demonstrating the importance of modelling life-cycle effects. Observing, as we do, large sibling effects at the start of the life-cycle may be particularly worrying in the presence of credit constraints that may be binding at young ages.

Having established that paternal earnings are important in determining sibling correlations raises further issues that can be addressed in the future. In essence, one would like to better understand the factors operating behind the two components of sibling correlations identified in this paper. Endowments and social networks are two dimensions for future investigations. Assessing the importance of these factors is not new to the literature; however, looking at them using multi-person models of earnings dynamics similar to the ones of this paper may provide new insights on these long-standing issues. 


\section{Appendix}

Minimum Distance estimation of the model is based on imposing the moment restrictions implied by the model on empirical second moments estimated from the data.

Moment restrictions for the extended RG model of permanent earnings are as follows:

Father's covariance structure

$$
\mathrm{E}\left(\mathrm{y}_{\mathrm{ijt}}^{\mathrm{F}} \mathrm{y}^{\mathrm{F}} \mathrm{ijr}\right)=\left[\left(\sigma_{\alpha}^{2}+\sigma_{\mu}^{2}\right)+\left(\sigma_{\beta}^{2}+\sigma_{\lambda}^{2}\right) \mathrm{A}_{\mathrm{it}} \mathrm{A}_{\mathrm{ir}}+\left(\sigma_{\alpha \beta}+\sigma_{\mu \lambda}\right)\left(\mathrm{A}_{\mathrm{it}}+\mathrm{A}_{\mathrm{ir}}\right)\right] \pi_{\mathrm{t}} \pi_{\mathrm{r}} ;
$$

Son's covariance structure

$$
\begin{aligned}
\mathrm{E}\left(\mathrm{y}^{\mathrm{Sb}}{ }_{\mathrm{ijt}} \mathrm{y}^{\mathrm{Sb}}{ }_{\mathrm{ijr}}\right)= & {\left[\left(\sigma_{\alpha}^{2}+\sigma_{\mu}^{2}+\sigma_{\delta}^{2}\right)+\left(\sigma_{\beta}^{2}+\sigma_{\lambda}^{2}+\sigma_{\phi}^{2}\right) \mathrm{A}_{\mathrm{it}} \mathrm{A}_{\mathrm{ir}}+\right.} \\
& \left.\left(\sigma_{\alpha \beta}+\sigma_{\mu \lambda}+\sigma_{\delta \phi}\right)\left(\mathrm{A}_{\mathrm{it}}+\mathrm{A}_{\mathrm{ir}}\right)\right] \pi_{\mathrm{t}} \pi_{\mathrm{r}}, \mathrm{b}=1,2 ;
\end{aligned}
$$

Father-Son covariance structure

$$
\mathrm{E}\left(\mathrm{y}_{\mathrm{ijt}}^{\mathrm{F}} \mathrm{y}^{\mathrm{Sb}}{ }_{\mathrm{kjr}}\right)=\left[\sigma_{\mu}^{2}+\sigma_{\lambda}^{2} \mathrm{~A}_{\mathrm{it}} \mathrm{A}_{\mathrm{kr}}+\left(\sigma_{\mu \lambda}\right)\left(\mathrm{A}_{\mathrm{it}}+\mathrm{A}_{\mathrm{kr}}\right)\right] \pi_{\mathrm{t}} \pi_{\mathrm{r}}, \mathrm{b}=1,2
$$

Son-Son covariance structure

$$
\mathrm{E}\left(\mathrm{y}^{\mathrm{S} 1}{ }_{\mathrm{ijt}} \mathrm{y}_{\mathrm{kjr}}^{\mathrm{S} 2}\right)=\left[\left(\sigma_{\mu}^{2}+\sigma_{\delta}^{2}\right)+\left(\sigma_{\lambda}^{2}+\sigma_{\phi}^{2}\right) \mathrm{A}_{\mathrm{it}} \mathrm{A}_{\mathrm{kr}}+\left(\sigma_{\mu \lambda}+\sigma_{\delta \phi}\right)\left(\mathrm{A}_{\mathrm{it}}+\mathrm{A}_{\mathrm{kr}}\right)\right] \pi_{\mathrm{t}} \pi_{\mathrm{r}}
$$

RG intercepts and slopes are identified by age. Idiosyncratic parameters are identified by individual earnings moments. Intergenerational parameters are identified by Father-Son earnings moments. Sibling parameters are identified by Son-Son earnings moments, so that the difference between siblings moments and intergenerational moments identifies residual sibling parameters. Using RG parameters we can decompose the total sibling correlation of permanent earnings into its intergenerational and residual sibling components over the life cycle, obtaining equation (8) of the main text:

$$
\rho^{S}(A)=\rho^{I}(A)+\rho^{R}(A)
$$

where

$$
\begin{array}{ll}
- & \rho^{\mathrm{I}}(\mathrm{A})=\left[\sigma_{\mu}^{2}+\sigma_{\lambda}^{2} \mathrm{~A}^{2}+2 \sigma_{\mu \lambda} \mathrm{A}\right] / \operatorname{var}(\mathrm{y}(\mathrm{A})), \\
\text { - } & \rho^{\mathrm{R}}(\mathrm{A})=\left[\sigma_{\delta}^{2}+\sigma_{\phi}^{2} \mathrm{~A}^{2}+2 \sigma_{\delta \phi} \mathrm{A}\right] / \operatorname{var}(\mathrm{y}(\mathrm{A})) \text { and } \\
\text { - } & \operatorname{var}(\mathrm{y}(\mathrm{A}))=\left[\left(\sigma_{\alpha}^{2}+\sigma_{\mu}^{2}+\sigma_{\delta}^{2}\right)+\left(\sigma_{\beta}^{2}{ }_{\beta}+\sigma_{\lambda}^{2}{ }_{\lambda}+\sigma_{\phi}^{2}\right) \mathrm{A}^{2}+2\left(\sigma_{\alpha \beta}+\sigma_{\mu \lambda}+\sigma_{\delta \phi}\right) \mathrm{A}\right] .
\end{array}
$$


Within person moment restrictions for the member-specific AR(1) model are as follows:

$$
E\left(v^{h}{ }_{i j t} v^{h}{ }_{i j s}\right)=\left\{d_{0 c} \eta_{c} \sigma_{0 h}^{2}+d_{d}\left[\sigma_{\varepsilon h}^{2}+\operatorname{Var}\left(u_{i j t-1}^{h}\right) \rho_{h}^{2}\right]+d_{1}\left[E\left(u^{h}{ }_{i j t-1} u^{h}{ }_{i j t-s}\right) \rho_{h}\right]\right\} \tau_{t} \tau_{s}
$$

where $d_{0 c}$ is a dummy for variances in the first year of observation of cohort c, $d_{d c}$ is a dummy for variances in subsequent years and $d_{1}$ is a dummy for covariances.

Since we allow for cross-member correlations of transitory shocks, the model yields restrictions on transitory earnings also for cross-member moments:

$$
\mathrm{E}\left(\mathrm{v}_{\mathrm{ijt}}^{\mathrm{h}} \mathrm{v}_{\mathrm{kjs}}^{1}\right)=\sigma_{\mathrm{hl}}\left[\mathrm{d}_{\mathrm{d}}+\left(1-\mathrm{d}_{\mathrm{d}}\right)\left(\mathrm{d}_{\mathrm{t}>\mathrm{s}} \rho_{\mathrm{h}}^{\mid \mathrm{t}-\mathrm{sl}}+\mathrm{d}_{\mathrm{s}<\mathrm{t}} \rho_{\mathrm{l}}^{\mid \mathrm{t}-\mathrm{sl}}\right)\right] \tau_{\mathrm{t}} \tau_{\mathrm{s}}
$$

where $d_{t>s}\left(d_{s<t}\right)$ indicates whether $t>s(t<s)$. 
Appendix Table: Estimates of period factor loadings for the main model

\begin{tabular}{cccccc}
\hline & \multicolumn{2}{c}{$\begin{array}{c}\text { Permanent } \\
\text { component, } \pi_{\mathrm{t}}\end{array}$} & & \multicolumn{2}{c}{$\begin{array}{c}\text { Transitory } \\
\text { component, } \tau_{\mathrm{t}}\end{array}$} \\
\cline { 2 - 3 } 1980 & Coeff. & S.E. & & Coeff. & S.E. \\
\cline { 2 - 3 } 1981 & 1 & & & 1 & \\
1982 & 1.1673 & 0.0300 & & 1 & \\
1983 & 1.2109 & 0.0367 & & 1 & \\
1984 & 1.0702 & 0.0381 & & 1 & \\
1985 & 1.0829 & 0.0402 & & 0.9137 & 0.0146 \\
1986 & 0.9851 & 0.0317 & & 0.8970 & 0.0162 \\
1987 & 1.1133 & 0.0349 & & 0.8774 & 0.0154 \\
1988 & 1.2033 & 0.0378 & & 0.9004 & 0.0158 \\
1989 & 1.1858 & 0.0385 & & 0.9652 & 0.0176 \\
1990 & 1.3074 & 0.0422 & & 0.9592 & 0.0164 \\
1991 & 1.3523 & 0.0420 & & 0.9320 & 0.0155 \\
1992 & 1.3039 & 0.0408 & & 0.9758 & 0.0170 \\
1993 & 1.3399 & 0.0417 & & 0.9634 & 0.0157 \\
1994 & 1.4507 & 0.0470 & & 0.9371 & 0.0171 \\
1995 & 1.3605 & 0.0445 & & 0.8968 & 0.0161 \\
1996 & 1.4037 & 0.0459 & & 0.8831 & 0.0152 \\
1997 & 1.4126 & 0.0468 & & 0.8489 & 0.0149 \\
1998 & 1.3560 & 0.0451 & & 0.8467 & 0.0146 \\
1999 & 1.3554 & 0.0454 & & 0.8479 & 0.0142 \\
2000 & 1.3477 & 0.0464 & & 0.8657 & 0.0150 \\
2001 & 1.3040 & 0.0449 & & 0.8749 & 0.0144 \\
2002 & 1.2833 & 0.0444 & & 0.8963 & 0.0145 \\
2003 & 1.2485 & 0.0438 & & 0.9401 & 0.0158 \\
2004 & 1.1878 & 0.0418 & & 0.9089 & 0.0148 \\
2005 & 1.1392 & 0.0398 & & 0.8667 & 0.0141 \\
2006 & 1.0572 & 0.0375 & & 0.8391 & 0.0136 \\
\hline & & & & &
\end{tabular}




\section{References}

Altonji, Joseph G. and Dunn Thomas A.. "Family Incomes and Labor Market Outcomes of Relatives.” In Ehrenberg, R., ed., Research in Labor Economics, Vol. 12, Greenwich CT: Jai Press, 1991, pp. 246-69.

Anti Nilsen, Øivind, Vaage, Kjell, Aakvik, Arild and Jacobsen, Karl. "Intergenerational Earnings Mobility Revisited: Estimates Based on Lifetime Earnings.” Scandinavian Journal of Economics, 114(1), 2012, pp. 1-23.

Baker, Michael. "Growth-Rate Heterogeneity and the Covariance Structure of Life-Cycle Earnings.” Journal of Labor Economics, 1997, 15(2), pp. 338-75.

Becker, Gary S. and Tomes Nigel. "An Equilibrium Theory of the Distribution of Income and Intergenerational Mobility.” Journal of Political Economy 87 (), 1979, pp. 1153-89.

Black, Sandra E. and Devereux, Paul J.. "Recent Developments in Intergenerational Mobility." in O. Ashenfelter and D. Card, eds., Handbook of Labor Economics, Vol. 4A. Amsterdam: Elsevier Science, North Holland, 2011, pp. .

Baker, Michael and Solon, Gary. "Earnings Dynamics and Inequality among Canadian Men, 1976-1992: Evidence from Longitudinal Income Tax Records." Journal of Labor Economics, 2003, 21(2), pp. 267-88.

Bingley, Paul, Cappellari, Lorenzo and Westergård-Nielsen, Niels. "Unemployment Insurance, Wage Dynamics and Inequality over the Life Cycle", unpublished manuscript, The Danish National Centre for Social Research, September 2012.

Björklund, Anders and Jännti, Markus. "Intergenerational Income Mobility and the Role of Family Background." in W. Salverda, B. Nolan and T. Smeeding, eds., The Oxford Handbook of Economic Inequality, Oxford: Oxford University Press, 2009, pp. 491521.

Björklund, Anders and Jännti, Markus. "How Important is Family Background for LaborEconomic Outcomes?” Labour Economics, 2012, 19(4), pp. 491-521.

Björklund, Anders, Jäntti, Markus and Lindquist, Matthew J. "Family Background and Income during the Rise of the Welfare State: Brother Correlations in Income for Swedish Men Born 1932-1968” Journal of Public Economics, 2009, 93(5-6), pp. 67180 .

Björklund, Anders, Lindahl Lena, and Lindquist Matthew J. "What More Than Parental Income, Education and Occupation? An Exploration of What Swedish Siblings Get from Their Parents." The B.E. Journal of Economic Analysis \& Policy, Berkeley Electronic Press, vol. 10(1), 2010, pages 102. 
Black, Sandra E., Devereux, Paul J., and Salvanes Kjell G.. "The More the Merrier? The Effect of Family Size and Birth Order on Children's Education.” The Quarterly Journal of Economics, vol. 120(2), 2005, pages 669-700.

Bohlmark, Anders and Lindquist, Matthew J.. "Life-Cycle Variations in the Association between Current and Lifetime Income: Replication and Extension for Sweden.” Journal of Labor Economics, 2006, 24(4), pages 879-900.

Chamberlain, Gary. "Panel Data.", in Z. Griliches and M. Intriligator, eds., Handbook of Econometrics, Vol. 2, Amsterdam: Elsevier Science, North Holland, 1984, pp. .

Grawe, Nathan D.. "Lifecycle Bias in Estimates of Intergenerational Earnings Persistence." Labour Economics, 2006, 13(5), pp. 551-70.

Griliches, Zvi. "Sibling Models and Data in Economics: Beginnings of a Survey." Journal of Political Economy, 1979, 87(5), pp. S37-S64.

Haider Stephen J.. "Earnings Instability and Earnings Inequality of Males in the United States: 1967-1991.” Journal of Labor Economics, 2001, 19(4), pp. 799-836.

Haider, Steven J. and Solon, Gary. "Life-Cycle Variation in the Association between Current and Lifetime Earnings.” American Economic Review, 2006, 96(4), pp. 1308-20.

Hause, John C. "The Fine Structure of Earnings and the On-the-Job Training Hypothesis.", Econometrica, 1980, 48(4), pp.1013-29.

Hotz, Joseph, V. and Pantano, Juan (2011) "Strategic Parenting, Birth Order and School Performance", unpublished manuscript.

Hyslop, Dean R. "Rising U.S. Earnings Inequality and Family Labor Supply: The Covariance Structure of Intrafamily Earnings.” American Economic Review, 2001, 91(4), pp. 75577.

Jenkins, Stephen J.. "Snapshots versus Movies: 'Lifecycle Biases' and the Estimation of Intergenerational Earnings Inheritance.” European Economic Review, 1987, 31(5), pp. $1149-58$.

Mazumder, Bhashkar. "Fortunate Sons: New Estimates of Intergenerational Mobility in the United States Using Social Security Earnings Data." Review of Economics and Statistics, 2005, 87(2), pp. 235-55.

Meghir, Costas and Pistaferri, Luigi. "Earnings, Consumption, and Life Cycle Choices.", in O. Ashenfelter and D. Card, eds., Handbook of Labor Economics, Vol. 4A. Amsterdam: Elsevier Science, North Holland, 2011, pp. . 
Moffitt Robert and Gottschalk, Peter. "Trends in the Variances of Permanent and Transitory Earnings in the U.S. and Their Relation to Earnings Mobility.", Boston College Working Papers in Economics 444, Boston College Department of Economics, 1995

Moffitt Robert and Gottschalk Peter. "Trends in the Transitory Variance of Male Earnings: Methods and Evidence.” Journal of Human Resources, 2012, 47(1), pp. 204-36.

Nybom, Martin and Stuhler, Jan. "Heterogeneous Income Profiles and Life-Cycle Bias in Intergenerational Mobility Estimation.”, IZA DP No. 5697, 2011

Ostrovsky, Yuri “The Correlation of Spouses' Permanent and Transitory Earnings and Family Earnings Inequality in Canada” Labour Economics, 2012, 19(5), pp. 756-68.

Page, Marianne and Solon, Gary. "Correlations between Sisters and Neighbouring Girls in their Subsequent Income as Adults.” Journal of Applied Econometrics, 2003, 18(5), pp. $545-62$.

Page Marianne and Solon, Gary. "Correlations between Brothers and Neighboring Boys in Their Adult Earnings: The Importance of Being Urban." Journal of Labor Economics, 2003, 21(4), pp. 831-56.

Solon, Gary, Corcoran, Mary, Gordon, Roger and Laren, Deborah. “A Longitudinal Analysis of Sibling Correlations in Economic Status.” Journal of Human Resources, 1991, 26(3), pp. 509-34

Solon, Gary. "Intergenerational Mobility in the Labor Market." in O. Ashenfelter and D. Card, eds., Handbook of Labor Economics, Vol. 3A. Amsterdam: Elsevier Science, North Holland, 1999, pp. 1761-1800. 


\begin{tabular}{|c|c|c|c|c|c|c|c|}
\hline & & \multicolumn{3}{|c|}{$\begin{array}{l}\text { (1) Sample without earnings } \\
\text { selection }\end{array}$} & \multicolumn{3}{|c|}{ (2) Estimating sample } \\
\hline & & Father & Son 1 & Son2 & Father & Son 1 & Son2 \\
\hline \multirow{2}{*}{\multicolumn{2}{|c|}{$\begin{array}{l}\text { Individuals } \\
\text { Observations }\end{array}$}} & 301696 & 301696 & 89051 & 245952 & 245952 & 66237 \\
\hline & & 6261749 & 3404154 & 922805 & 5397161 & 2979859 & 754717 \\
\hline \multirow[t]{3}{*}{1985} & Earnings (DKR 2000) & 318.51 & 200.86 & 199.90 & 318.32 & 202.54 & 201.92 \\
\hline & SD Earnings & 163.09 & 97.85 & 91.32 & 131.95 & 93.15 & 86.91 \\
\hline & Age & 37.94 & 23.35 & 23.00 & 37.92 & 23.35 & 23.00 \\
\hline \multirow[t]{3}{*}{1995} & Earnings (DKR 2000) & 355.71 & 207.65 & 198.87 & 352.50 & 210.23 & 201.84 \\
\hline & SD Earnings & 202.55 & 126.44 & 117.84 & 168.57 & 119.21 & 110.92 \\
\hline & Age & 47.88 & 24.93 & 24.01 & 47.86 & 24.99 & 24.08 \\
\hline \multirow[t]{3}{*}{2005} & Earnings (DKR 2000) & 369.92 & 312.73 & 299.13 & 364.65 & 318.28 & 306.02 \\
\hline & SD Earnings & 226.09 & 186.69 & 167.34 & 173.93 & 156.52 & 143.29 \\
\hline & Age & 54.65 & 31.75 & 30.76 & 54.64 & 31.98 & 31.03 \\
\hline
\end{tabular}


Table 2: Permanent Earnings - Estimates of Random Growth parameters

\begin{tabular}{lccc}
\hline & A. Starting level & \\
\hline & Coeff. & S.E. & Share \\
\cline { 2 - 4 }$\sigma_{\alpha}^{2}$ (Individual) & 0.0577 & 0.0048 & 0.42 \\
$\sigma_{\mu}^{2}$ (Intergenerational) & 0.0253 & 0.0021 & 0.18 \\
$\sigma^{2}$ (Sibling residual) & 0.0545 & 0.0048 & 0.40
\end{tabular}

B. Growth rates

\begin{tabular}{|c|c|c|c|}
\hline & Coeff. & S.E. & Share \\
\hline$\sigma_{\beta}^{2}$ (Individual) & 0.00003 & 0.00001 & 0.07 \\
\hline$\sigma_{\lambda}^{2}$ (Intergenerational) & 0.00013 & 0.00001 & 0.34 \\
\hline$\sigma_{\phi}^{2}($ Sibling residual $)$ & 0.0002 & 0.00002 & 0.59 \\
\hline \multicolumn{4}{|c|}{ C. Covariance } \\
\hline & Coeff. & S.E. & Age* \\
\hline$\sigma_{\alpha \beta}$ (Individual) & -0.0002 & 0.0002 & 28 \\
\hline$\sigma_{\mu \lambda}$ (Intergenerational) & -0.0014 & 0.0001 & 32 \\
\hline$\sigma_{\delta \phi}($ Sibling residual $)$ & -0.0033 & 0.0003 & 38 \\
\hline
\end{tabular}


Table 3: Transitory Earnings - Estimates of member-specific AR(1)

\begin{tabular}{lcc}
\hline \multicolumn{3}{c}{ A. Variance of shocks $\left(\sigma_{\varepsilon}^{2}\right)$} \\
\hline & Coeff & S.E. \\
Father & 0.2495 & 0.0060 \\
Son1 & 0.4006 & 0.0117 \\
Son2 & 0.4017 & 0.0124
\end{tabular}

B. Covariance of shocks $\left(\sigma_{\mathrm{hl}}\right)$

\begin{tabular}{|c|c|c|}
\hline & Coeff & S.E. \\
\hline Father-Son 1 & -0.0007 & 0.0024 \\
\hline Father-Son2 & 0.0089 & 0.0035 \\
\hline Son1-Son2 & 0.0215 & 0.0034 \\
\hline \multicolumn{3}{|c|}{ C. Autoregressive coefficient ( $\rho$ ) } \\
\hline & Coeff & S.E. \\
\hline Father & 0.5925 & 0.0057 \\
\hline Son 1 & 0.5497 & 0.0076 \\
\hline Son2 & 0.4790 & 0.0116 \\
\hline \multicolumn{3}{|c|}{ D. Initial condition $\left(\sigma_{0}^{2}\right)$} \\
\hline & Coeff & S.E. \\
\hline Father & 0.3671 & 0.0138 \\
\hline Son 1 & 0.2894 & 0.0490 \\
\hline Son 2 & 0.2423 & 0.0421 \\
\hline \multicolumn{3}{|c|}{ E. Birth cohort $(\eta, 1940-42=1)$} \\
\hline & Coeff & S.E. \\
\hline $1943-1945$ & 0.9069 & 0.0416 \\
\hline $1946-1948$ & 0.7572 & 0.0356 \\
\hline $1949-1951$ & 0.6634 & 0.0341 \\
\hline $1952-1954$ & 0.7986 & 0.0409 \\
\hline $1955-1957$ & 0.9296 & 0.0528 \\
\hline $1958-1960$ & 0.9650 & 0.0744 \\
\hline $1961-1963$ & 1.4181 & 0.2656 \\
\hline $1964-1966$ & 1.4358 & 0.2553 \\
\hline $1967-1969$ & 1.7710 & 0.3040 \\
\hline $1970-1972$ & 2.1918 & 0.3713 \\
\hline $1973-1975$ & 2.0185 & 0.3400 \\
\hline $1976-1979$ & 1.9454 & 0.3274 \\
\hline $1979-1981$ & 2.0476 & 0.3427 \\
\hline
\end{tabular}


Table 4: Robustness checks

4.1 Triplets-only sample

\begin{tabular}{lccc}
\hline & A. Starting level & \\
\hline & Coeff. & S.E. & Share \\
\cline { 2 - 4 }$\sigma_{\alpha}^{2}$ (Individual) & 0.0636 & 0.0089 & 0.40 \\
$\sigma_{\mu}^{2}$ (Intergenerational) & 0.0230 & 0.0033 & 0.15 \\
$\sigma_{\delta}^{2}$ (Sibling residual) & 0.0713 & 0.0080 & 0.45
\end{tabular}

B. Growth rates

\begin{tabular}{lccc}
\hline & Coeff. & S.E. & Share \\
\cline { 2 - 4 }$\sigma_{\beta}^{2}$ (Individual) & 0.0001 & 0.00002 & 0.11 \\
$\sigma_{\lambda}^{2}$ (Intergenerational) & 0.0002 & 0.00002 & 0.34 \\
$\sigma_{\phi}^{2}$ (Sibling residual) & 0.0003 & 0.00003 & 0.55 \\
& \multicolumn{3}{c}{} \\
& C. Covariance \\
\hline & Coeff. & S.E. & Age* \\
\cline { 2 - 4 }$\sigma_{\alpha \beta}$ (Individual) & -0.0004 & 0.0004 & 29 \\
$\sigma_{\mu \lambda}$ (Intergenerational) & -0.0015 & 0.0002 & 30 \\
$\sigma_{\delta \phi}$ (Sibling residual) & -0.0040 & 0.0004 & 36 \\
\hline
\end{tabular}

4.2 Correlated sibling effects

\begin{tabular}{lccc}
\hline & A. Starting level & \\
\hline & Coeff. & S.E. & Share \\
\cline { 2 - 4 }$\sigma_{\alpha}^{2}$ (Individual) & 0.0558 & 0.0035 & 0.45 \\
$\sigma_{\mu}^{2}$ (Intergenerational) & 0.0449 & 0.0037 & 0.17 \\
$\sigma_{\delta}^{2}$ (Sibling residual) & 0.0699 & 0.0054 & 0.38 \\
$\sigma_{\mu \delta}$ (Covariance) & -0.0235 & 0.0037 &
\end{tabular}

B. Growth rates

\begin{tabular}{lccc}
\hline & Coeff. & S.E. & Share \\
\cline { 2 - 4 }$\sigma_{\beta}^{2}$ (Individual) & 0.0001 & 0.00003 & 0.22 \\
$\sigma_{\lambda}^{2}$ (Intergenerational) & 0.0001 & 0.00002 & 0.30 \\
$\sigma_{\phi}^{2}$ (Siblings residual) & 0.0002 & 0.00004 & 0.48 \\
$\sigma_{\lambda \phi}^{2}$ (Covariance) & 0.00004 & 0.00002 & \\
& & & \\
\hline & C. Covariance & & Age* \\
\hline & Coeff. & S.E. & 33 \\
$\sigma_{\alpha \beta}$ (Individual) & -0.0010 & 0.0002 & 36 \\
$\sigma_{\mu \lambda}$ (Intergenerational) & -0.0012 & 0.0001 & 39 \\
$\sigma_{\delta \phi}$ (Siblings residual) & -0.0027 & 0.0003 & \\
\hline
\end{tabular}


Table 5: Nested models

5.1 Intergenerational model

\begin{tabular}{|c|c|c|c|}
\hline \multicolumn{4}{|c|}{ A. Starting level } \\
\hline & Coeff. & S.E. & Share \\
\hline$\sigma_{\alpha}^{2}($ Individual $)$ & 0.0933 & 0.0068 & 0.78 \\
\hline$\sigma_{\mu}^{2}($ Intergenerational $)$ & 0.0261 & 0.0022 & 0.22 \\
\hline \multicolumn{4}{|c|}{ B. Growth rates } \\
\hline & Coeff. & S.E. & Share \\
\hline$\sigma_{\beta}^{2}$ (Individual) & 0.00010 & 0.00001 & 0.40 \\
\hline$\sigma_{\lambda}^{2}($ Intergenerational $)$ & 0.00015 & 0.00001 & 0.60 \\
\hline \multicolumn{4}{|c|}{ C. Covariance } \\
\hline & Coeff. & S.E. & Age* \\
\hline$\sigma_{\alpha \beta}$ (Individual) & -0.0017 & 0.0003 & 38 \\
\hline$\sigma_{\mu \lambda}$ (Intergenerational) & -0.0015 & 0.0001 & 31 \\
\hline
\end{tabular}

5.2 Siblings model

\begin{tabular}{|c|c|c|c|}
\hline \multicolumn{4}{|c|}{ A. Starting level } \\
\hline \multirow{3}{*}{$\begin{array}{l}\sigma_{\alpha}^{2} \text { (Individual) } \\
\sigma_{\delta}^{2}(\text { Siblings })\end{array}$} & Coeff. & S.E. & Share \\
\hline & 0.0429 & 0.0128 & 0.59 \\
\hline & 0.0299 & 0.0091 & 0.41 \\
\hline \multicolumn{4}{|c|}{ B. Growth rates } \\
\hline \multirow{4}{*}{$\begin{array}{l}\sigma_{\beta}^{2}(\text { Individual }) \\
\sigma_{\phi}^{2}(\text { Siblings })\end{array}$} & Coeff. & S.E. & Share \\
\hline & 0.0001 & 0.00004 & 0.51 \\
\hline & 0.0001 & 0.00004 & 0.49 \\
\hline & \multicolumn{3}{|c|}{ C. Covariance } \\
\hline & Coeff. & S.E. & Age* \\
\hline$\sigma_{\alpha \beta}$ (Individual) & -0.0016 & 0.0005 & 33 \\
\hline$\sigma_{\delta \phi}($ Siblings $)$ & -0.0017 & 0.0005 & 35 \\
\hline
\end{tabular}


Table 6: Permanent earnings with mother's schooling

A. Mother education

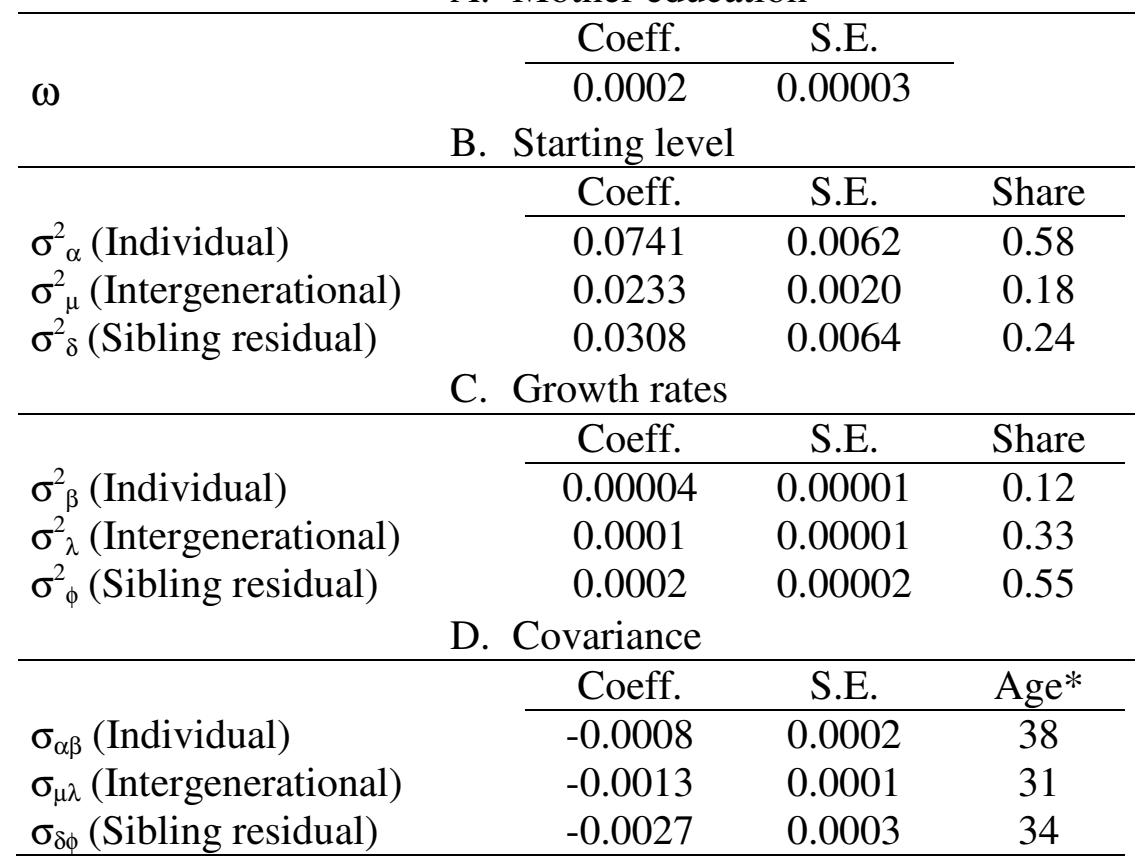


Table 7: Permanent earnings with differential intergenerational transmission

\begin{tabular}{|c|c|c|c|c|}
\hline \multicolumn{5}{|c|}{ A. Starting level } \\
\hline & Coeff. & S.E. & Share S1 & Share S2 \\
\hline$\sigma_{\alpha}^{2}($ Individual $)$ & 0.0487 & 0.01409 & 0.30 & 0.30 \\
\hline$\sigma_{\mu 1}^{2}($ Intergenerational Son 1$)$ & 0.0191 & 0.00807 & 0.12 & \\
\hline$\sigma_{\mu 2}^{2}($ Intergenerational Son 2$)$ & 0.0206 & 0.00812 & & 0.12 \\
\hline$\sigma_{\mu 12}($ Intergenerational Son1 Son 2) & 0.0035 & 0.00563 & & \\
\hline$\sigma_{\delta}^{2}($ Sibling residual $)$ & 0.0925 & 0.01551 & 0.58 & 0.58 \\
\hline \multicolumn{5}{|c|}{ B. Growth rates } \\
\hline & Coeff. & S.E. & Share S1 & Share S2 \\
\hline$\sigma_{\beta}^{2}$ (Individual) & 0.0001 & 0.00003 & \multicolumn{2}{|c|}{0.12} \\
\hline$\sigma_{\lambda}^{2}$ (Intergenerational) & 0.0002 & 0.00002 & \multicolumn{2}{|c|}{0.36} \\
\hline$\sigma_{\phi}^{2}($ Sibling residual $)$ & 0.0003 & 0.00004 & \multicolumn{2}{|c|}{0.54} \\
\hline \multicolumn{5}{|c|}{ C. Covariance } \\
\hline & Coeff. & S.E. & \multicolumn{2}{|c|}{ Age* $^{*}$} \\
\hline$\sigma_{\alpha \beta}($ Individual $)$ & -0.0005 & 0.00049 & \multicolumn{2}{|c|}{29} \\
\hline$\sigma_{\mu \lambda}$ (Intergenerational) & -0.0016 & 0.00022 & \multicolumn{2}{|c|}{30} \\
\hline$\sigma_{\delta \phi}($ Sibling residual $)$ & -0.0040 & 0.00055 & \multicolumn{2}{|c|}{36} \\
\hline
\end{tabular}


Figure 1: Intergenerational and sibling associations of earnings
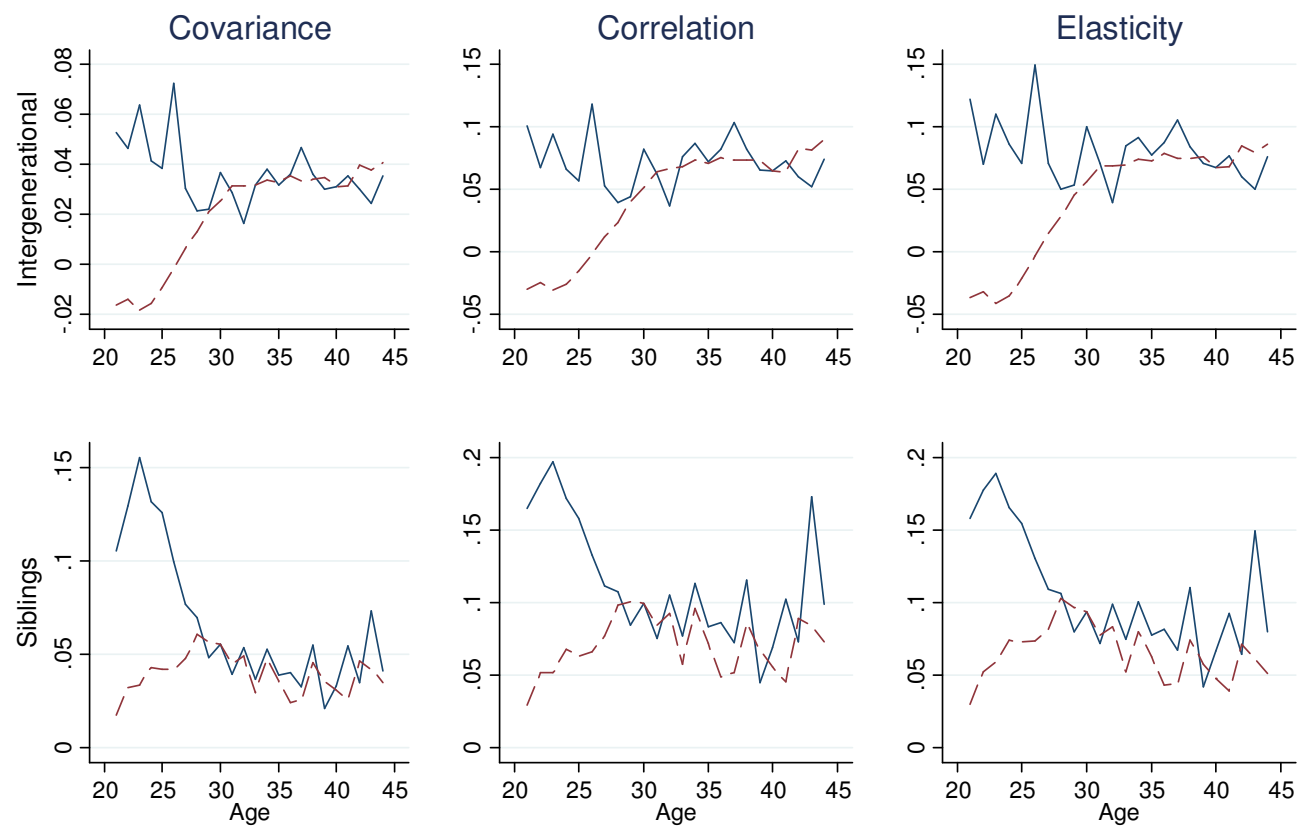
Figure 2: Decomposition of life-cycle earnings variance

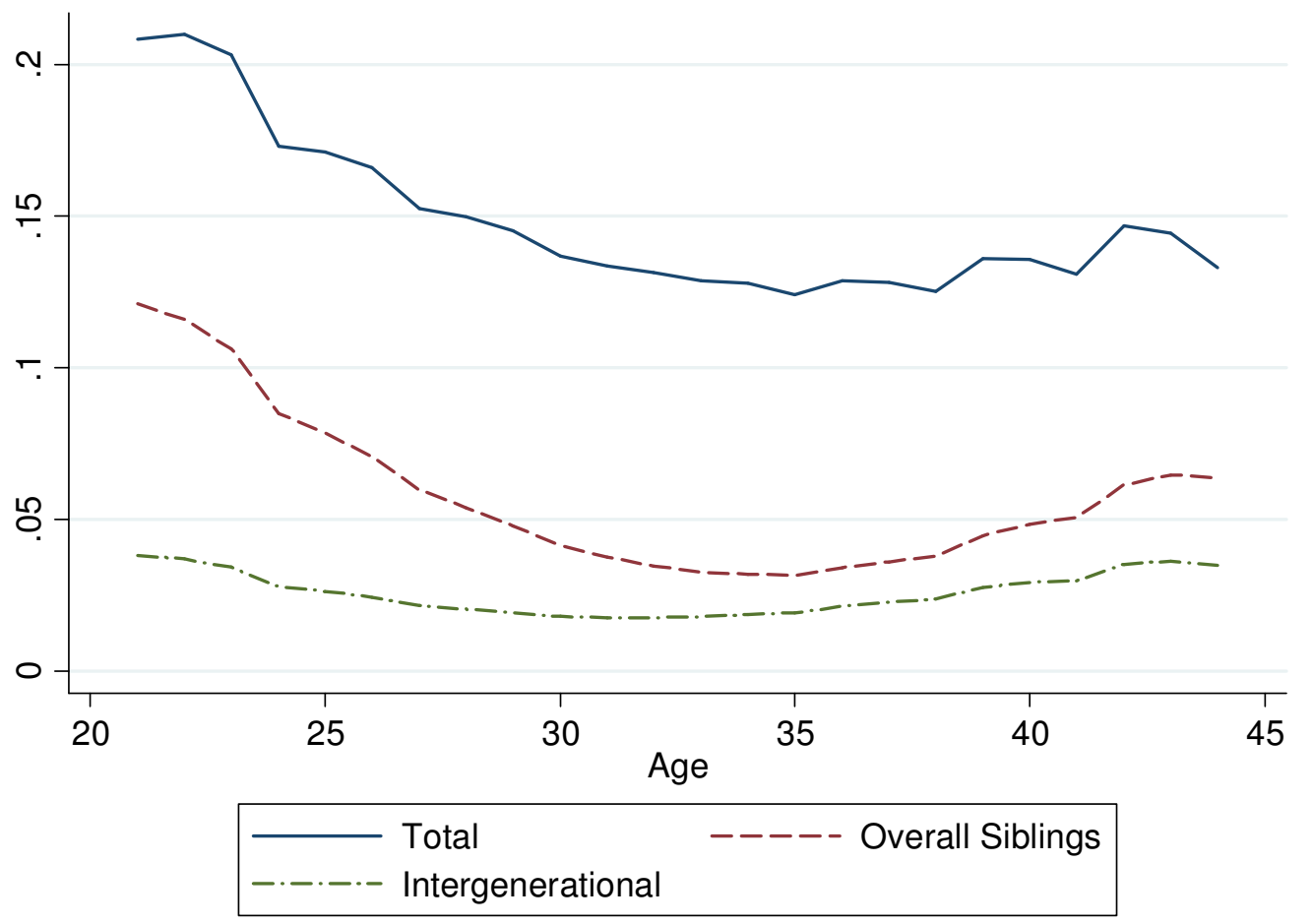


Figure 3: Decomposition of sibling correlation

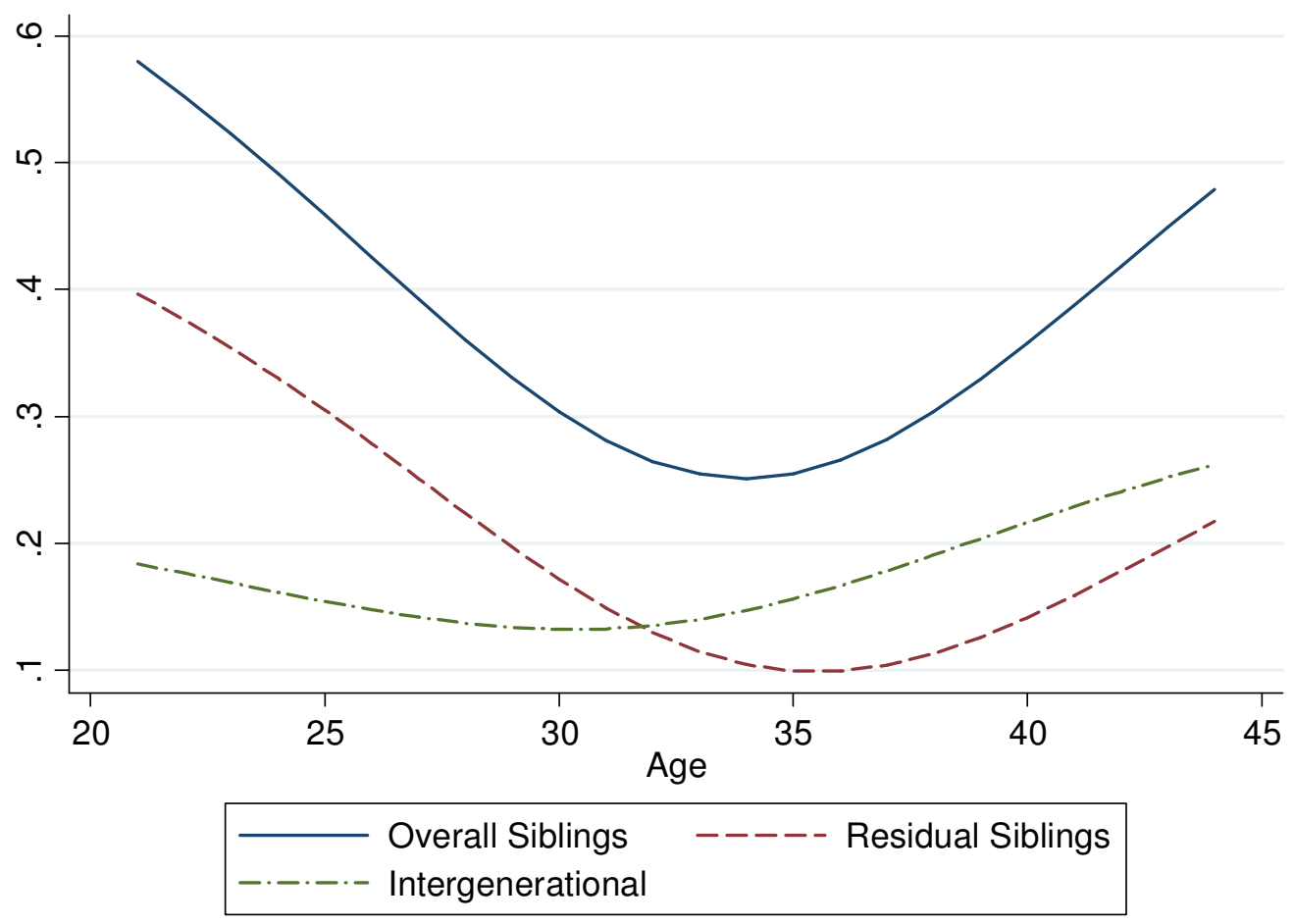


Figure 4: Decomposition of sibling correlation; robustness checks
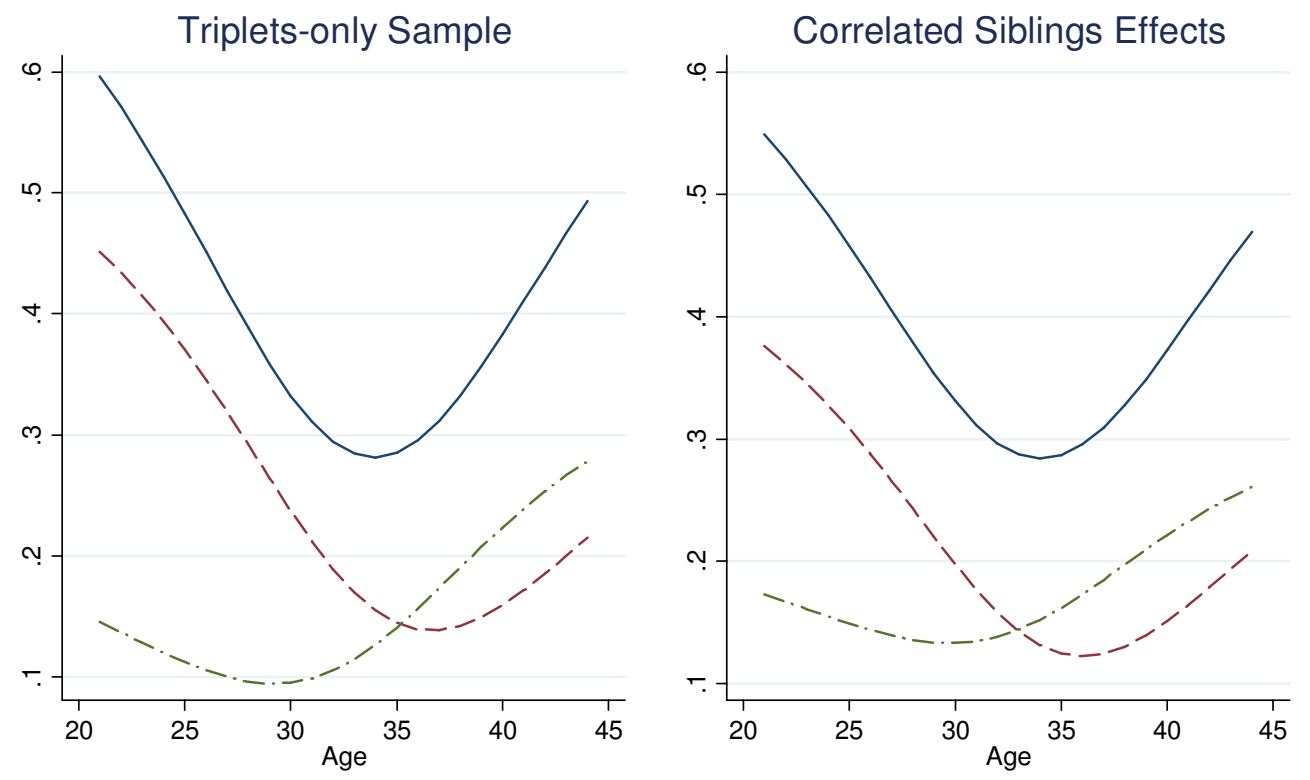

Overall Siblings

Residual Siblings Intergenerational 